\title{
EVALUATION OF FRAGILITY FUNCTIONS WITH POTENTIAL RELEVANCE FOR USE IN NEW ZEALAND
}

\author{
Trevor Z. Yeow ${ }^{1}$, Timothy J. Sullivan ${ }^{2}$ and Kenneth J. Elwood ${ }^{3}$
}

(Submitted February 2018; Reviewed June 2018; Accepted July 2018)

\begin{abstract}
One barrier to adopting seismic loss estimation frameworks in New Zealand engineering practice is the lack of relevant fragility functions which provide probabilities of exceeding certain levels of damage (e.g. cracking of gypsum wallboards) for a given demand (e.g. interstorey drifts). This study seeks to address this need for four different building components; interior full-height steel-framed plasterboard partition walls, unbraced suspended ceilings, precast concrete cladding, and steel beam-column joints with extended bolted end-plate connections. Fragility functions were sourced from literature, and their potential for use in New Zealand is evaluated considering similarities in component detailing with local practices. Modifications to a number of fragility functions, including generalizations for easier adoption in practice, are proposed. A loss estimation case study of a 4-storey steel moment-resisting frame is performed to investigate the significance of fragility function selection. It is shown that the definition of damage states can have a noticeable influence on the assessment of incurred repair cost of individual building components. This indicates that fragility functions should be carefully selected, particularly if the performance evaluation of each individual component is of utmost importance. However, the observed difference in expected annual repair cost of the entire building was small, indicating that in cases where fragility functions are not readily applicable for use in New Zealand, other fragility functions may be used as placeholders without drastically altering the outcome of loss analysis for the entire building.
\end{abstract}

\section{INTRODUCTION}

Damage to building components, such as structural elements, partitions, and ceilings, have led to large losses associated with repair works, disruptions in building functionality, and injuries during past earthquake events [1-8]. In engineering design, drift or deformation limits are often imposed to limit damage at the serviceability limit state and extensive damage at the ultimate limit state shaking levels [9]. However, there is uncertainty in the building component capacity arising from variation in material properties, connection detailing, and component design. As such, the likelihood of damage for each individual building component at all shaking intensities, including the two limit states, is not explicitly considered in design, and the likely loss in an earthquake is uncertain.

One rational means of quantifying likely losses is to adopt procedures such as the Pacific Earthquake Engineering Research center's Performance Based Earthquake Engineering framework [10]. This framework comprises of four steps, which are to (i) perform seismic hazard assessment to obtain annual rates of exceeding various levels of ground shaking intensity, (ii) use structural analysis to assess the building's response to a given ground shaking intensity, (iii) predict damage in the building based on the building's response, and (iv) estimate the resulting losses. In some cases, such as building-level assessments, the damage may be linked directly to the ground shaking intensity. One common method to link damage to either the building's response (measured as an engineering demand parameter, $E D P$, such as peak interstorey drift or peak total floor acceleration) or ground shaking intensity (measured as an intensity measure, $I M$, such as peak ground acceleration or spectral acceleration) is to use fragility functions. Fragility functions describe the probability of exceeding a given level of damage, which is often described as a damage state $(D S)$. An example of this for steel beam-column joints is shown in Figure 1.

Several computer programmes are available to perform seismic loss estimation [12-14]. These have libraries of fragility functions covering a range of building components. There are also numerous component-level fragility functions available in literature, most of which are based on international studies. As damage observed is often dependent on the detailing and design of the building components, these fragilities may not be readily applicable for use in New Zealand due to differences in engineering and construction practice. This is considered to be one of the main barriers in adopting seismic loss estimation in New Zealand practice.

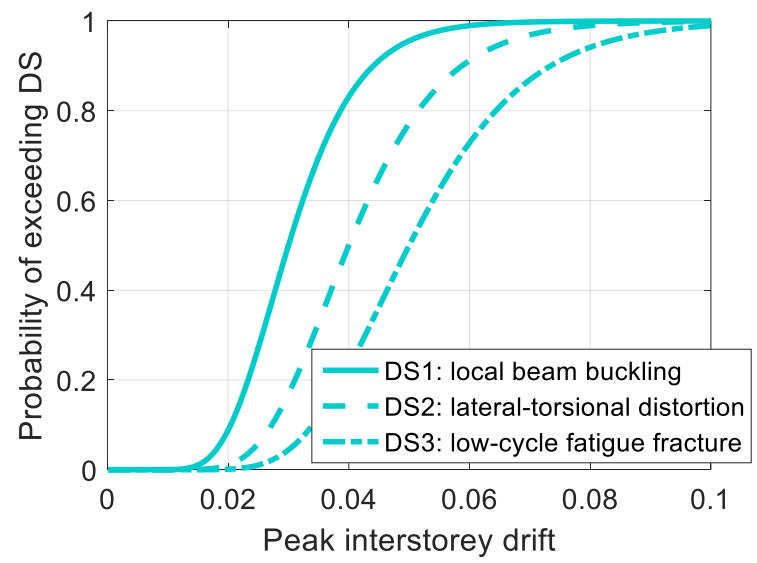

Figure 1: Fragility for welded steel beam-column joints with reduced beam sections [11].

\footnotetext{
1 Corresponding Author, Project Researcher, Earthquake Research Institute, University of Tokyo, Tokyo trevoryeow@eri.u-tokyo.ac.jp

2 Associate Professor, University of Canterbury, Christchurch (Member)

3 Professor, University of Auckland, Auckland (Member)
} 
This study aims to identify (and if necessary, modify) fragility functions from literature which are relevant for use in New Zealand. The scope will be limited to four components in commercial buildings; (i) interior partitions, (ii) suspended ceilings, (iii) exterior precast concrete cladding, and (iv) steel moment-resisting beam-column joints. The first three are selected due to the observed widespread damage to these components during past seismic events as shown in Figure 2 [1$3]$, the potential for injury due to failure of these components [4], or their significant contribution to seismic loss based on past research studies [5-8]. Steel beam-column joints are also selected as they are reflective of modern construction around New Zealand, particularly in Christchurch, where over $80 \%$ of new total floor area constructed since the $22^{\text {nd }}$ of February 2011 event are supported by steel or steel-composite construction $[15,16]$. In addition to sourcing these fragility functions, comparisons with fragility functions available in the Performance Assessment Calculation Tool, PACT [13], will be made considering a case study building to demonstrate the importance of fragility function selection. Discussions regarding differences observed and recommendations for these fragility functions for use in New Zealand are then provided.

\section{OVERVIEW OF FRAGILITY FUNCTIONS}

\section{Description and Application of Fragility Functions}

As mentioned previously, fragility functions describe the probability of exceeding a certain level of damage, commonly referred to as "damage states", for a given demand. An example of damage states for steel beams could be (i) onset of local buckling, (ii) lateral-torsional distortion in the beam hinge region, and (iii) fracture of the beam as suggested by Deierlein and Victor [11] for welded steel beam-column joints with reduced beam sections. Generally, each damage state requires a different type of repair or replacement, or results in a different consequence (e.g. cladding panels may cause injuries when significantly damaged, even though it may already need complete replacement at lower levels of damage). Fragility functions are usually, but not always (depends on goodness-offit checks), based on the lognormal distribution. If a lognormal distribution is followed, the exceedance probability can be calculated from Equation 1.

$$
P\left(D S \geq D S_{i}\right)=\Phi\left(\frac{\ln \left(x_{\text {demand }} / x_{m}\right)}{\beta}\right)
$$

where $D S_{i}$ is the $i^{\text {th }}$ damage state, $x_{\text {demand }}$ is the demand (e.g. interstorey drift), $x_{m}$ and $\beta$ are the median and dispersion of the lognormal distribution of the capacity, and $\Phi$ is the normal distribution function. An example of fragility function is shown earlier in Figure 1 for steel beams, where each curve represents the probability of exceeding its corresponding damage state. The probability of incurring a given damage state at a given demand is the difference between the exceedance probability curves.

\section{Methods to Develop Fragility Functions}

One of the most detailed publications regarding the derivation of fragilities is that of Porter et al. [18]. Six different approaches were described as follows:

- Actual Failure $E D P$ - this is used where the $E D P$ which triggered a damage state is known, and a probabilistic distribution (usually a lognormal distribution) is fit to the $E D P$ values.

- Bounding $E D P$ - this is used where the peak $E D P$ which each data sample had been subjected to is known but not all samples reached the damage state of interest. The samples are grouped into bins based on EDP, and the probability of failure for each bin is obtained. A probabilistic distribution is then fit to the failure probabilities.

- Capable $E D P$ - this is used where none of the data samples reached the damage state of interest. In this case, a weighting factor approach is adopted to estimate the median EDP considering how close each sample is to reaching the damage state.

- Derived fragility - this is based on the use of mechanics or models to derive the fragility rather than experimental data or site observations.

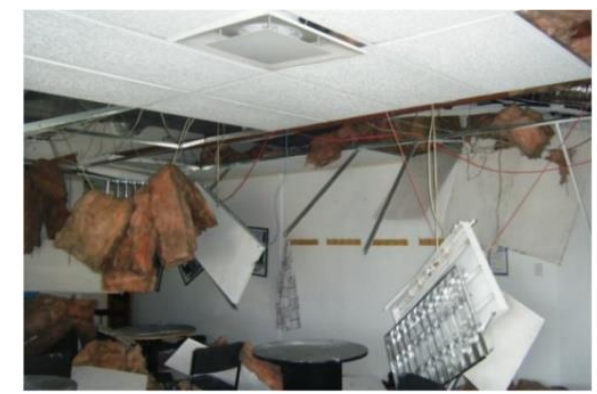

(b)

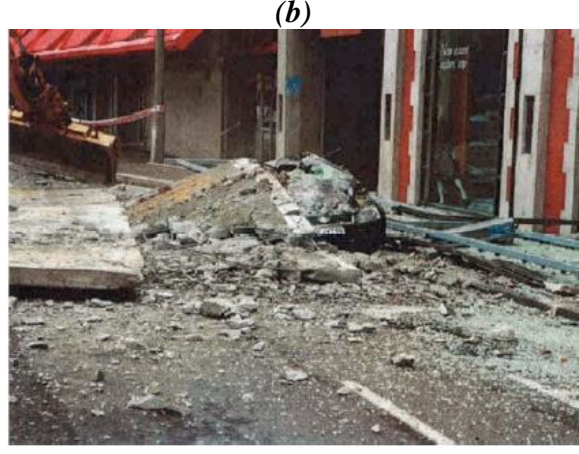

(c)

Figure 2: Component damage during the 22 $2^{\text {nd }}$ of February 2011 Christchurch earthquake; (a) interior partitions, (b) suspended ceilings [2], and (c) precast concrete panels [17]. 
- $\quad$ Expert opinion - this is based on results from surveys of several experts.

- Updating with new data - this is used where newer data is available, and older existing fragility functions are modified accordingly

There are several other considerations described by Porter et al. [18], including the need for goodness-of-fit evaluations such as the Lilliefors test [19], proposing methods to modify fragility functions which cross where the probability of incurring a given damage state may be negative which is nonsensical, and assessing the quality of the fragility functions. Interested readers are encouraged to review the document by Porter et al. [18] which provides more information on the derivation methods and other considerations.

\section{INTERIOR FULL-HEIGHT STEEL-FRAMED PLASTERBOARD PARTITIONS}

\section{Detailing of Partitions}

The most common type of interior partition walls in commercial buildings in New Zealand are cold-formed steel-framed plasterboard partitions. These are either full-height (e.g. built to floor above) or partial-height (e.g. built to ceiling level, then connected to floor above by braces). Only the former is considered here as there is limited research on the latter. Common details of full-height partitions based on New Zealand practice are shown in Figure 3 (from Tasligedik et al. [20]), where both the steel studs and gypsum boards are fixed to the

External Connection

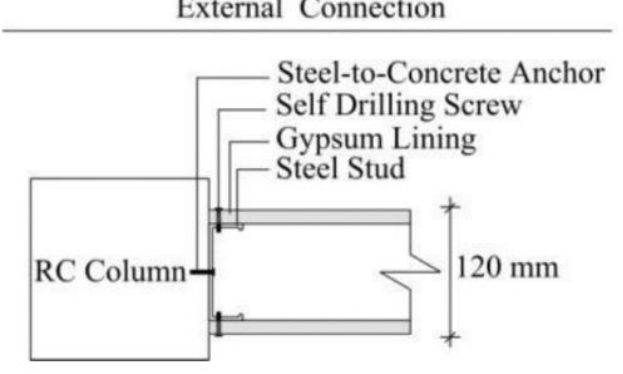

(a) tracks by screws. This is similar to a "commercial fixedconnection" type used in the US. It should, however, be noted that there are some differences in stud-to-track connection detailing allowed in the US versus that in New Zealand, as the former allows multiple screws to be used on each side of a stud to connect to the tracks, while in New Zealand only one is allowed. This may cause potential differences in the resulting fragility functions. While alternate detailing is available in New Zealand where the gypsum boards are not screwed directly to the tracks, Tasligedik et al. [20] indicated that this is not common practice.

\section{Existing Full-Height Steel-Framed Partition Fragility Functions}

Partition damage tends to be associated with peak interstorey drifts $[21,22]$. Two existing fragility functions are examined in detail in this study. The first is by Miranda and Mosqueda [21], who proposed fragility functions which were originally used in PACT [13] based on 54 data samples from six different experimental research studies [23-28], almost all of which have similar detailing to that used in New Zealand (i.e. a single screw being used to connect the stud to tracks on each side of the stud similar to that shown in Figure 3). Miranda and Mosqueda [21] developed the fragility functions by firstly identifying the interstorey drifts which triggered the onset of a damage state of interest, and then applying the "Actual Failure EDP" approach described by Porter et al. [18]. Three separate damage states were considered, and their definitions are as shown in Table 1.

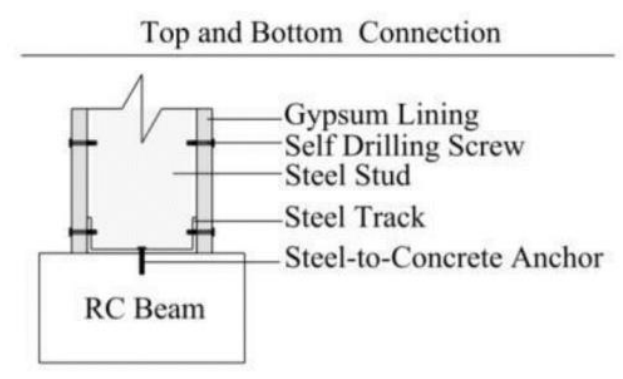

(b)

Figure 3: Typical partition connection detailing; (a) typical side connection to column [20], and (b) typical bottom connection to beam [20].

Table 1: Interior full-height steel-framed partition wall damage state descriptions.

\begin{tabular}{|c|c|c|}
\hline Damage state & Miranda and Mosqueda [21] definition & Mosqueda [22] definition \\
\hline 0 & $\mathrm{~N} / \mathrm{A}$ & $\begin{array}{ll}\text { - } & \text { Minor cracking of wallboards or tape } \\
\text { - } & \text { Visible screw pop-out } \\
\text { - } & \text { Light warping of tape }\end{array}$ \\
\hline 1 & $\begin{array}{l}\text { - } \quad \text { Minor cracking of wallboards or tape } \\
\text { - } \quad \text { Warping of tape } \\
\text { - }\end{array}$ & $\begin{array}{l}\text { - } \quad \text { Cracking of wallboard } \\
\text { - } \quad \text { Warping or cracking of tape } \\
\text { - } \quad \text { Slight crushing of wall panel at corners } \\
\text { - } \quad \text { Significant screw pop-out }\end{array}$ \\
\hline 2 & $\begin{array}{l}\text { - Severe cracking, crushing, or buckling of } \\
\text { wallboards } \\
\text { - } \quad \text { Bending of boundary studs }\end{array}$ & $\begin{array}{l}\text { - } \quad \text { Severe cracking or crushing of gypsum } \\
\text { wallboards } \\
\text { - } \quad \text { Moderate corner gap opening } \\
\text { - } \quad \text { Bending of boundary studs }\end{array}$ \\
\hline 3 & $\begin{array}{l}\text { - Severe damage to wallboards and } \\
\text { screws } \\
\text { - Damage to steel framing requiring } \\
\text { replacement }\end{array}$ & $\begin{array}{ll}\text { - } & \text { Buckling of studs and tearing of tracks } \\
\text { - } & \text { Bending of top track } \\
\text { - } & \text { Large gap openings } \\
\text { - } & \text { Displaced walls }\end{array}$ \\
\hline
\end{tabular}


One limitation of the damage state descriptions provided by Miranda and Mosqueda [21] is that some of the damage described in damage state 1 may be minor and may also result from unavoidable wear and tear. Mosqueda [22] stated that this level of damage may not necessarily require repairs for functionality, and as such introduced damage state 0 . They also revised the definition of the other damage states as shown in Table 1. Based on the new definitions, the interstorey drifts which triggered the onset of each damage state were again identified from the 54 samples considered previously, and a further 11 additional tests from two other research studies [29, 30], which again have nearly identical detailing to that used in New Zealand, were included. This revised fragility function replaced that from Miranda and Mosqueda [21] in PACT [13]. The median and dispersion of the fragility functions from both studies are shown in Table 2. It should be noted that the repair actions proposed for DS1, DS2, and DS3 are nearly identical between the two studies despite the different damage state descriptions.

It should also be mentioned that there are other fragility functions available in the literature for this type of partition [28, 31]. However, the data which these are based on was either already considered in Miranda and Mosqueda [21] and/or Mosqueda [22], or are based on a much smaller data sample which resulted in lower quality fragility functions.

\section{Modifications to Full-Height Steel-Framed Partition Fragility Functions}

As the fragility functions by Miranda and Mosqueda [21] and Mosqueda [22] are based on partitions with similar detailing to that used in New Zealand, no significant modifications are required. However, there are a few other relevant research studies which had not been incorporated, namely those by Tasligedik et al. [20] and Petrone et al. [31], and hence the fragility functions by Mosqueda [22] are modified here accordingly.

Tasligedik et al. [20] performed a single test of an interior steelframed partition wall in New Zealand, and provided a brief description of observed damage. Based on the revised definitions from Mosqueda [22], damage states 1 and 2 could be identified. However, there was insufficient information to identify the onset of damage state 3 .

Petrone et al. [31] tested six different interior steel-framed partition wall configurations. However, the third sample tested used steel studs at a spacing of $900 \mathrm{~mm}$ while the fifth and sixth had a wider cavity which required staggered stud locations; both details of which are uncommon in New Zealand. Petrone et al. [31] provided drift values based on their own damage state definition which is similar to that provided by Mosqueda [22] and is deemed sufficient for the purposes of this study. The drifts which triggered the onset of each damage state from Tasligedik et al. [20] and Petrone et al. [31] are shown in Table 3 . These drifts were then added to the dataset used by Mosqueda [22] to derive a new set of fragility functions following the "Actual Failure EDP" approach from Porter et al. [18]. The final set of fragility functions, hereby termed the "adopted fragility", is also included in Table 3.

\section{Evaluation of Full-Height Steel-Famed Partition Fragility Functions}

A comparison of the adopted fragility functions with those of Miranda and Mosqueda [21] and Mosqueda [22] are shown in Figure 4. It can be seen that there is almost no difference between the adopted fragility functions and those of Mosqueda [22]. This is reasonable since both sets follow the same damage state definitions, and the addition of 4 new data entries is unlikely to change the fragility by Mosqueda [22] significantly since it is already based off 65 data entries. However, there are significant differences with those by Miranda and Mosqueda [21]. As these fragility functions are mostly based off the same data but with different damage state definitions yet requires similar repair actions for each damage state, this highlights the importance of the damage state definitions in loss estimation.

The relevance of the full-height steel-framed partition wall fragility functions shown here to the seismic performance of buildings will be highlighted through a case study later in the paper.

Table 2: Existing fragility functions based on peak interstorey drift.

\begin{tabular}{|c|c|c|c|c|}
\hline \multirow{2}{*}{$\begin{array}{l}\text { Damage } \\
\text { state }\end{array}$} & \multicolumn{2}{|c|}{ Miranda and Mosqueda [21] } & \multicolumn{2}{|c|}{ Mosqueda [22] } \\
\hline & Median & Dispersion & Median & Dispersion \\
\hline 0 & \multicolumn{2}{|c|}{$\mathrm{N} / \mathrm{A}$} & 0.0029 & 0.5 \\
\hline 1 & 0.0021 & 0.60 & 0.0059 & 0.38 \\
\hline 2 & 0.0071 & 0.45 & 0.0106 & 0.31 \\
\hline 3 & 0.0120 & 0.45 & 0.0234 & 0.18 \\
\hline
\end{tabular}

Table 3: Additional partition experimental data and final adopted fragility functions based on peak interstorey drift.

\begin{tabular}{ccccccc} 
Damage & Tasligedik & \multicolumn{3}{c}{ Petrone et al. [31] } & \multicolumn{2}{c}{ Adopted fragility } \\
\cline { 3 - 7 } state & et al. [20] & Test 1 & Test 2 & Test 4 & Median & Dispersion \\
\hline 1 & 0.0040 & 0.0034 & 0.0016 & 0.0032 & 0.0056 & 0.43 \\
2 & 0.0075 & 0.0087 & 0.0091 & 0.0116 & 0.0105 & 0.31 \\
3 & - & 0.0278 & 0.0292 & 0.0161 & 0.0234 & 0.19
\end{tabular}

*Damage state 3 not included for Tasligedik et al. [19] as insufficient information available to identify its onset, and several tests excluded from Petrone et al. [30] as the detailing used is not consistent with New Zealand practice 


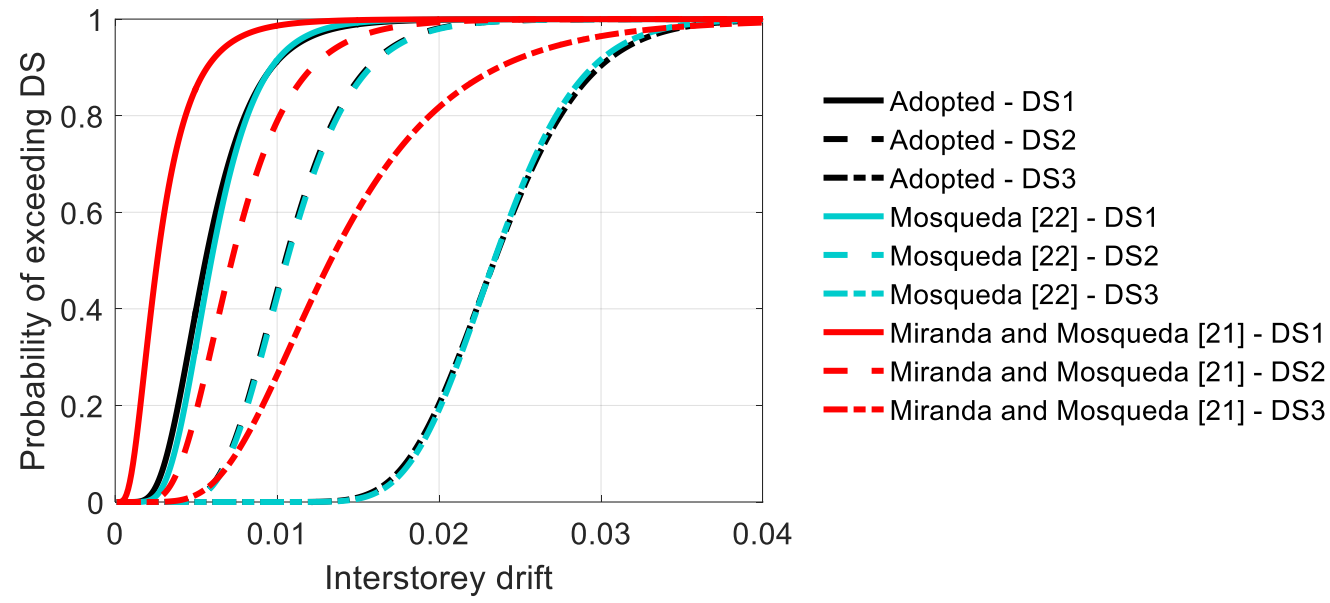

Figure 4: Comparison of fragility functions for interior full-height steel-framed partition walls.

\section{UNBRACED SUSPENDED CEILINGS}

\section{Importance and Detailing of Suspended Ceilings}

There are multiple approaches to install suspended ceilings [32]. One option is to connect the ceiling to the wall along two adjacent sides and have it floating on the other two sides as shown in Figure 5. This enables relative movement between opposite ends of the ceiling without imparting significant force in the ceiling components. If the size of the ceiling is large enough so that the ceiling grid and grid-to-wall connections are unable to support the design lateral load, other options include (i) fixing the ceiling on all four sides but implementing seismic gaps to enable movement, or (ii) have a fully floating ceiling with braces. This study will focus on the fixed-floating unbraced suspended ceiling configuration shown in Figure 5 which, based on design guides [33-35], are often the first option considered, and other options are generally only selected if the ceiling area is too large. Furthermore, there exist approaches to derive fragility functions for fixed-floating unbraced suspended ceilings based on New Zealand experimental tests which are discussed in the following section.

\section{Existing Fragility Functions for Unbraced Suspended Ceilings}

Ceiling damage is often associated with either peak total floor acceleration, $a_{f t}$, or peak total ceiling acceleration, $a_{c t}[32,36$, 37]. Three existing fragility functions for unbraced suspended ceilings are examined here. The first is by Soroushian et al. [36], which used experimental results from three separate experimental studies [38-40] to propose fragilities for a range

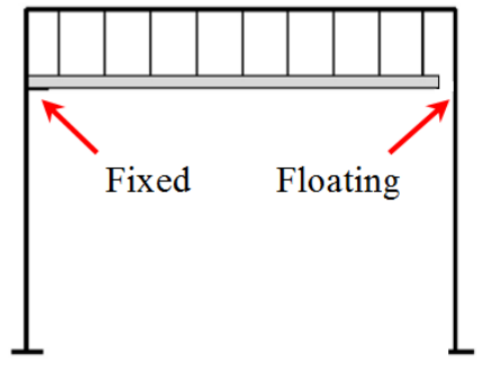

(a) of ceiling conditions based on $a_{f t}$, such as whether lateral restraints were provided, if piping interaction was observed, or whether the loading was horizontal or three-dimensional. Damage was classified into three categories, "slight", "moderate", and "extensive", the definitions of which are shown in Table 4. Only a single fragility was provided for unbraced suspended ceilings, and the effect of ceiling sizes are not distinguished.

Another set of fragility functions for suspended ceilings has been proposed by Soroushian [37] which has been implemented into PACT [13] considering $a_{f t}$. The unbraced fragility functions proposed were based on four shake table tests performed by Ryu et al. [38] of square ceiling systems with various areas, a unit weight of $6.8 \mathrm{~kg} / \mathrm{m}^{2}$ and $0.6 \mathrm{~m}$ by $0.6 \mathrm{~m}$ ceiling grids. There are two key differences between this set of fragility functions and those proposed by Soroushian et al. [36]. The first is that the definition of damage states is different as shown in Table 4 . The second is that fragility functions are provided for four different ranges of ceiling sizes shown in Table 5. The fragility functions from both Soroushian et al. [36] and Soroushian [37] are shown in Table 6.

The final approach discussed here was proposed by Dhakal et al. [32]. This is a mechanics based approach where the force demand for each ceiling component (e.g. tees, rivets, grid connections) is computed by multiplying the weight which the component supports with the grid acceleration. This force is then used to assess the probability of failure of individual ceiling components based on fragility functions derived from experimental testing by Paganotti et al. [41] of ceiling components used in New Zealand.

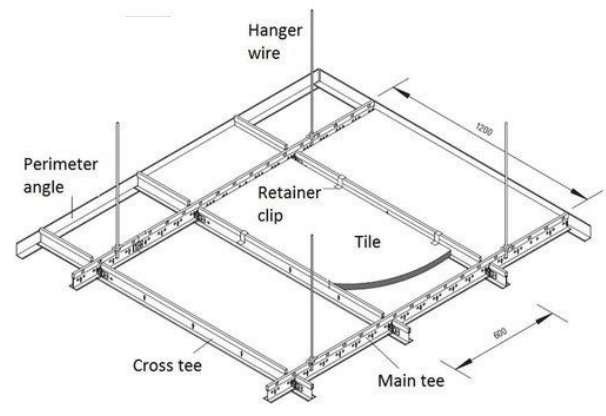

(b)

Figure 5: Typical detailing of suspended ceilings [32]; (a) side elevation, and (b) typical components. 
Table 4: Unbraced fixed-floating suspended ceiling damage state descriptions.

\begin{tabular}{|c|c|c|c|c|}
\hline $\begin{array}{l}\text { Damage } \\
\text { state }\end{array}$ & $\begin{array}{l}\text { Damage } \\
\text { level }\end{array}$ & Soroushian et al. [36] & Soroushian [37] & Dhakal et al. [32] \\
\hline 1 & Slight & $\begin{array}{l}\text { - Up to } 5 \% \text { of ceiling panels } \\
\text { dislodged } \\
\text { - } \quad \text { Damage to panels at sprinkler } \\
\text { heads may be visible } \\
\text { - } \quad \text { Slight damage to perimeter and } \\
\text { grid connections }\end{array}$ & $\begin{array}{c}5 \% \text { of ceiling grid and } \\
\text { tile damage }\end{array}$ & $\mathrm{N} / \mathrm{A}$ \\
\hline 2 & Moderate & 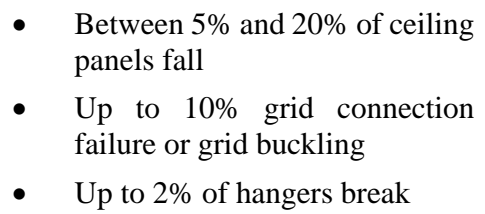 & $\begin{array}{l}30 \% \text { of ceiling grid and } \\
\text { tile damage }\end{array}$ & $\mathrm{N} / \mathrm{A}$ \\
\hline 3 & Extensive & $\begin{array}{l}\text { - Over } 20 \% \text { of ceiling area fall } \\
\text { - } \quad \begin{array}{l}\text { Significant damage to grid and } \\
\text { connections }\end{array}\end{array}$ & $\begin{array}{l}50 \% \text { of ceiling grid and } \\
\text { tile damage }\end{array}$ & $\begin{array}{l}\text { Failure of a single } \\
\text { ceiling element }\end{array}$ \\
\hline
\end{tabular}

Table 5: Ceiling area sizes considered by Soroushian [37].

\begin{tabular}{ccc} 
Ceiling Area $(\boldsymbol{A})$ & Representative area & Side length \\
\hline$A<23.2 \mathrm{~m}^{2}$ & $23.2 \mathrm{~m}^{2}$ & $4.88 \mathrm{~m}$ \\
$23.2 \mathrm{~m}^{2}<A<92.2 \mathrm{~m}^{2}$ & $58.1 \mathrm{~m}^{2}$ & $7.62 \mathrm{~m}$ \\
$92.2 \mathrm{~m}^{2}<A<232 \mathrm{~m}^{2}$ & $164 \mathrm{~m}^{2}$ & $12.8 \mathrm{~m}$ \\
$232 \mathrm{~m}^{2}<A$ & $232 \mathrm{~m}^{2}$ & $15.2 \mathrm{~m}$ \\
\hline
\end{tabular}

Table 6: Existing fragility functions for unbraced fixed-floating suspended ceilings in terms of peak total floor acceleration.

\begin{tabular}{|c|c|c|c|c|c|c|c|c|c|c|}
\hline \multirow{3}{*}{$\begin{array}{l}\text { Damage } \\
\text { state }\end{array}$} & \multirow{2}{*}{\multicolumn{2}{|c|}{$\begin{array}{c}\text { Soroushian et } \\
\text { al. [36] }\end{array}$}} & \multicolumn{8}{|c|}{ Soroushian [37] } \\
\hline & & & \multicolumn{2}{|c|}{$A<23.2 \mathrm{~m}^{2}$} & \multicolumn{2}{|c|}{$\begin{array}{c}23.2 \mathrm{~m}^{2}<A< \\
92.2 \mathrm{~m}^{2}\end{array}$} & \multicolumn{2}{|c|}{$\begin{array}{c}92.2 \mathrm{~m}^{2}<A< \\
232 \mathrm{~m}^{2}\end{array}$} & \multicolumn{2}{|c|}{$232 \mathrm{~m}^{2}<A$} \\
\hline & $x_{m}$ & $\beta$ & $\boldsymbol{x}_{m}$ & $\beta$ & $\boldsymbol{x}_{m}$ & $\beta$ & $x_{m}$ & $\beta$ & $\boldsymbol{x}_{m}$ & $\beta$ \\
\hline 1 & $0.85 \mathrm{~g}$ & 0.41 & $1.17 \mathrm{~g}$ & 0.30 & $1.01 \mathrm{~g}$ & 0.30 & $0.70 \mathrm{~g}$ & 0.30 & $0.56 \mathrm{~g}$ & 0.30 \\
\hline 2 & $1.23 \mathrm{~g}$ & 0.38 & $1.58 \mathrm{~g}$ & 0.30 & $1.45 \mathrm{~g}$ & 0.30 & $1.20 \mathrm{~g}$ & 0.30 & $1.08 \mathrm{~g}$ & 0.30 \\
\hline 3 & $1.79 \mathrm{~g}$ & 0.47 & $1.82 \mathrm{~g}$ & 0.30 & $1.69 \mathrm{~g}$ & 0.30 & $1.43 \mathrm{~g}$ & 0.30 & $1.31 \mathrm{~g}$ & 0.30 \\
\hline
\end{tabular}

One difference between this and the other two fragility functions is that only one damage state is considered as shown in Table 4, as Dhakal et al. [32] reasoned that brittle failure of a single ceiling component would cause cascading failure of other elements due to redistribution of load paths, and hence the entire ceiling would likely need to be replaced. Despite the difference in their damage state definition, Dhakal et al. [32] did demonstrate that the fragilities derived following this approach are consistent with ceiling failures observed from Ryu et al. [38] tests done on the $6.1 \mathrm{~m}$ by $6.1 \mathrm{~m}$ test frame; in which Ryu et al. [38] defines onset of collapse by $10 \%$ of the ceiling tiles falling.

Another difference is that the approach by Dhakal et al. [32] only considered $a_{c t}$ as the demand, compared to others which uses $a_{f t}$. On one hand, $a_{c t}$ is better correlated to ceiling damage since it is the acceleration demand on the ceiling itself, whereas the $a_{f t}$ needs to be paired with the ceiling properties (e.g. ceiling period) to better correlate with ceiling damage. On the other hand, the ceiling properties may not be readily known by the engineer, and they may not be familiar with methods to estimate floor spectra. As $a_{f t}$ may be directly obtained from structural analysis, $a_{f t}$ is perhaps more useful for practicing engineers to use rather than $a_{c t}$.

\section{Modifications to Unbraced Suspended Ceiling Fragility Functions}

Of the three existing fragility functions discussed, only the approach proposed by Dhakal et al. [32] will be adopted as (i) the methodology is based on test results from ceiling components used in New Zealand, and (ii) it can be easily adopted to consider ceilings of various sizes and shapes. However, the approach needs to be modified so that peak total floor acceleration is considered instead of peak total ceiling grid acceleration. To achieve this, results from Ryu et al. [38] will be used, as they had reported both $a_{c t}$ and $a_{f t}$ values from their ceiling experimental tests. Based on their findings for unbraced suspended ceilings on a $6.1 \mathrm{~m}$ by $6.1 \mathrm{~m}$ test frame, the probabilistic distribution of $a_{c t} / a_{f t}$ can be approximated by a lognormal distribution with a median value of 2.32 and a dispersion of 0.33 .

A Monte Carlo simulation approach is proposed here to combine the approach by Dhakal et al. [32] with the $a_{c t} / a_{f t}$ distribution from Ryu et al. [38]. Multiple simulations are performed at a given value of $a_{f t}$ to obtain the probability of ceiling failure. Each simulation follows the following steps:

1. Select a random value from the $a_{c t} / a_{f t}$ distribution and multiply this by $a_{f t}$ to obtain a random value of $a_{c t}$. 
2. Determine the demand forces within each ceiling component.

3. Use the component-level fragility functions from Dhakal et al. [32] to estimate the probability of failure of each component.

4. Select a value between 0 and 1 using a random number generator for each component. If the random value is less than the probability of failure of any component, it is assumed that the ceiling had failed.

This process is repeated for a wide range of $a_{f t}$. Once all $a_{f t}$ of interest are considered, the bounding $E D P$ value approach described by Porter et al. [18] is then used to derive fragility functions. Following the area ranges considered by Soroushian [37], the derived fragility functions are as shown in Table 7.

\section{Evaluation of Unbraced Suspended Ceiling Fragility Functions}

Comparison of the adopted fragility function against those from Soroushian et al. [36] and Soroushian [37] are shown in Figure 6 a for damage state 3 . For fair comparison, the adopted fragilities were derived considering a $0.6 \mathrm{~m}$ by $0.6 \mathrm{~m}$ grid size and $6.8 \mathrm{~kg} / \mathrm{m}^{2}$ ceiling mass. It can be seen that for small ceiling sizes, all three approaches have similar agreements. However for larger ceiling areas, the adopted fragility gives higher probability of failure.

The main reason for the difference at larger ceiling areas between the adopted approach compared to Soroushian et al. [36] is that, while Soroushian et al. [36] considered data from multiple research studies, only a few of these were unbraced. Those which were unbraced tended to have smaller ceiling areas, and hence derived fragility functions from Soroushian et al. [36] for unbraced ceilings would have a better fit for smaller ceiling areas as observed in Figure 6a.

The reason for the differences with Soroushian [37] is more complicated, and requires a more in-depth look at their approach to develop fragility functions which only considered a single fixed-floating ceiling specimen from Ryu et al. [38]. As sufficient data was not available to derive the relation between the median $a_{f t}$ which triggers ceiling damage and the linear length of the ceiling in the direction of excitation for fixedfloating ceilings, they considered three further ceiling samples from Ryu et al. [38] which uses seismic clips instead of having two ends being fully floating. They then assumed that the relationship between the median $a_{f t}$ and the linear length of the ceiling is linear for the specimens using seismic clips, and obtained a slope based on a linear regression considering only these three specimens as shown in Figure $6 \mathrm{~b}$ (tests 7, 11, and 13). Soroushian [37] then assumed that the median $a_{f t}$ to linear length of the ceiling relationship for fixed-floating ceilings also had the same slope, and fitted a linear line through this data point which is also shown in Figure 6b. However, if one assumes that a given ceiling component has a fixed capacity, then the relationship between acceleration and length should be hyperbolic in nature. This raises the question of whether the linear fit approach adopted by Soroushian [37] is reasonable. Alternatively, it could also be questioned whether the damage state definition adopted by Dhakal et al. [32] is too conservative, as the hyperbolic approximation would identify the first occurrence of failure but not necessarily complete ceiling failure. One further complication is that there may be some beam arching action occurring in the ceiling grids, meaning that not all seismic demand are necessarily transferred to the critical element which may increase the ceiling capacity, particularly if clips are used on free ends to provide some level of fixity [32]. If however a hyperbolic curve was fitted to the two smaller ceiling areas as shown in Figure 6b, it can be seen that the curve follows similar trends to the adopted fragility.

As it is unclear which fragility is more "accurate", the adopted approach will be taken as it is more conservative in its failure estimates. Furthermore, the mechanics based approach can be easily adopted to modify the fragilities for different ceiling grid sizes, mass, area, and aspect ratios.

Table 7: Derived unbraced fixed-floating suspended ceiling fragility functions based on peak total floor acceleration.

\begin{tabular}{ccc} 
Ceiling Area $(\boldsymbol{A})$ & $\boldsymbol{x}_{\boldsymbol{m}}$ & $\boldsymbol{\beta}$ \\
\hline$A<23.2 \mathrm{~m}^{2}$ & $1.85 \mathrm{~g}$ & 0.34 \\
$23.2 \mathrm{~m}^{2}<A<92.2 \mathrm{~m}^{2}$ & $1.18 \mathrm{~g}$ & 0.35 \\
$92.2 \mathrm{~m}^{2}<A<232 \mathrm{~m}^{2}$ & $0.71 \mathrm{~g}$ & 0.35 \\
$232 \mathrm{~m}^{2}<A$ & $0.59 \mathrm{~g}$ & 0.34 \\
\hline
\end{tabular}

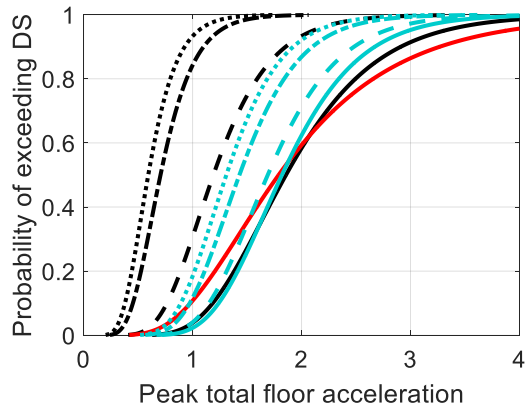

(a)

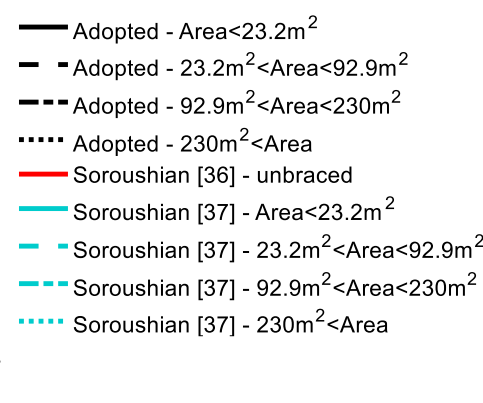

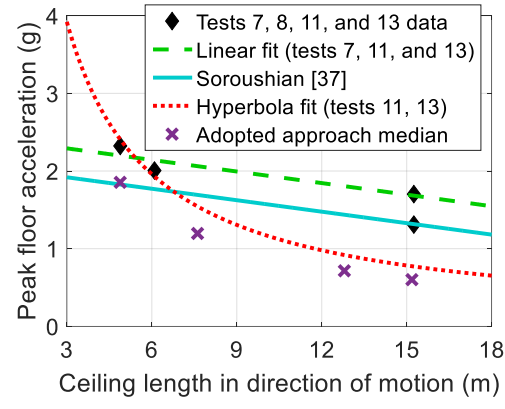

(b)

Figure 6: Evaluation of unbraced suspended ceiling fragility functions; (a) comparison of fragility functions, and (b) differences in best-fit approaches adopted for relationship between ceiling length in direction of motion and median peak total floor acceleration which triggers damage. 


\section{Adjustment for Ceiling Aspect Ratio and Size Distribution}

The adopted fragilities in Table 7 are based on square-shaped ceilings of sizes defined by Soroushian [37] and a ceiling unit weight of $6.8 \mathrm{~kg} / \mathrm{m}^{2}$. However, Dhakal et al. [32] had also provided information regarding the distribution of ceiling aspect ratio (e.g. ratio of the length of one side to another) and ceiling size commonly used in New Zealand. These two distributions are added to the Monte Carlo simulation approach between steps 1 and 2 to obtain random values for the ceiling dimensions. Based on this modified approach, generic fragility functions for New Zealand ceilings are shown in Table 8.

It should be noted that the ceiling sizes considered in Table 8 are different from those used by Soroushian [37], and correspond to the quarter percentiles in the ceiling size distribution from Dhakal et al. [32]. Furthermore, these fragilities were derived considering a unit weight of $1 \mathrm{~kg} / \mathrm{m}^{2}$. These values should be divided by the ceiling weight to obtain the fragilities in terms of $a_{f t}$. For example, if a ceiling has a unit weight of $10.8 \mathrm{~kg} / \mathrm{m}^{2}$, an area of $25 \mathrm{~m}^{2}$, and $1.2 \mathrm{~m}$ by $0.6 \mathrm{~m}$ grids, then the median $a_{f t}$ would be $0.66 \mathrm{~g}\left(7.08 \mathrm{~g} . \mathrm{kg} / \mathrm{m}^{2}\right.$, obtained from Table 8 for a ceiling size between $20 \mathrm{~m}^{2}$ and 30 $\mathrm{m}^{2}$ and using $1.2 \mathrm{~m}$ by $0.6 \mathrm{~m}$ grids, divided by $10.8 \mathrm{~kg} / \mathrm{m}^{2}$ ).

The potential relevance of unbraced suspended ceiling fragility functions on the seismic performance of buildings will be highlighted using a case study examined later in this paper.

\section{PRECAST CONCRETE CLADDING}

\section{Importance and Detailing of Precast Concrete Cladding}

Past studies on precast cladding have shown that most damage to precast concrete cladding tends to be concentrated at the connections $[3,17]$. Precast concrete claddings generally have bearing connections to the floor at their base to allow transfer of gravity forces, and movement connections to the beam above; the latter of which are usually the sole means by which an element can accommodate the drifts imposed during an earthquake. Movement connections traditionally uses a threaded rod [17]. In newer buildings, slotted connections, such as those shown in Figures 7a, are used instead. These are similar to the threaded rod connections, except that a slot has been fabricated into the angle which allows for additional movement prior to the rod itself deforming significantly. It should also be noted that precast cladding may also be connected to the columns; however, this will not be considered further in this study.

\section{Existing Fragility Functions for Precast Concrete Cladding}

Damage to precast concrete cladding elements are generally attributed to lateral displacement between the top and bottom connections [3, 17]. Two existing fragility functions are examined here for precast concrete cladding. The first is that by Hunt and Stojadinovic [42], which is based off a forcedisplacement relationship for threaded rod connections obtained from monotonic loading tests by McMullin et al. [43]. The threaded rod tested had a diameter of $25 \mathrm{~mm}$ and a length of $200 \mathrm{~mm}$. The damage states defined by Hunt and Stojadinovic [42] are as shown in Table 9.

The second fragility function examined is that from Baird [17] who tested six different threaded rod configurations considering different rod diameters and lengths for material supplied in New Zealand. The rod behaviour was reasonably well captured in a finite element model, which was later used to develop fragility functions for a wide range of rod diameters and lengths based on the damage state definition shown in Table 9. Baird [17] suggests that if a slotted connection is used, the median rod deformation can be increased by the allowable travel distance provided by the slot. Both fragility functions for a $200 \mathrm{~mm}$ long threaded rod with a $25 \mathrm{~mm}$ diameter are shown in Table 10.

Table 8: Derived unbraced suspended ceiling fragility functions based on peak total floor acceleration.

\begin{tabular}{ccccc}
\multirow{2}{*}{ Ceiling size } & \multicolumn{2}{c}{$\mathbf{0 . 6} \mathbf{~ m}$ by $\mathbf{0 . 6} \mathbf{~ m ~ g r i d ~}$} & \multicolumn{1}{c}{$\mathbf{1 . 2} \mathbf{~}$ by $\mathbf{0 . 6} \mathbf{~ m ~ g r i d ~}$} \\
\cline { 2 - 5 } & Median & Dispersion & Median & Dispersion \\
\hline$A<20 \mathrm{~m}^{2}$ & $12.4 \mathrm{~g} \cdot \mathrm{kg} / \mathrm{m}^{2}$ & & $9.28 \mathrm{~g} \cdot \mathrm{kg} / \mathrm{m}^{2}$ & \\
$20 \mathrm{~m}^{2}<A<30 \mathrm{~m}^{2}$ & $9.45 \mathrm{~g} \cdot \mathrm{kg} / \mathrm{m}^{2}$ & & $7.08 \mathrm{~g} \cdot \mathrm{kg} / \mathrm{m}^{2}$ & \\
$30 \mathrm{~m}^{2}<A<40 \mathrm{~m}^{2}$ & $7.95 \mathrm{~g} \cdot \mathrm{kg} / \mathrm{m}^{2}$ & 0.37 & 6.37 \\
$40 \mathrm{~m}^{2}<A$ & $6.18 \mathrm{~g} \cdot \mathrm{kg} / \mathrm{m}^{2}$ & & $6.02 \mathrm{~g} \cdot \mathrm{kg} / \mathrm{m}^{2}$ & \\
\hline
\end{tabular}

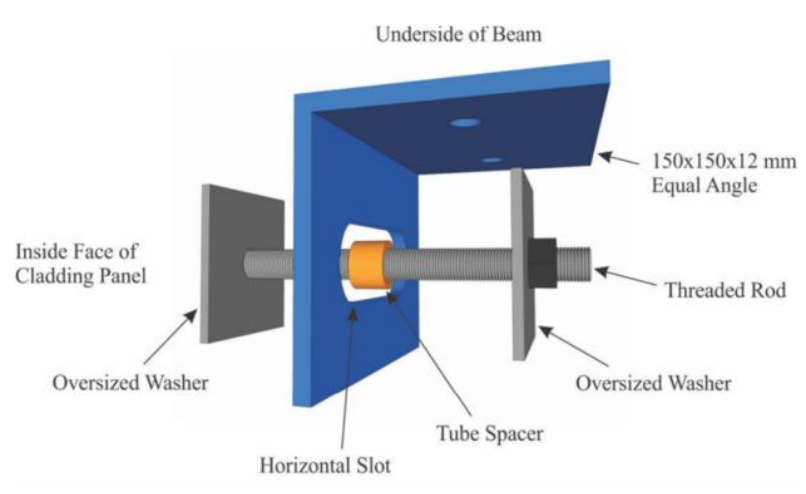

(a)

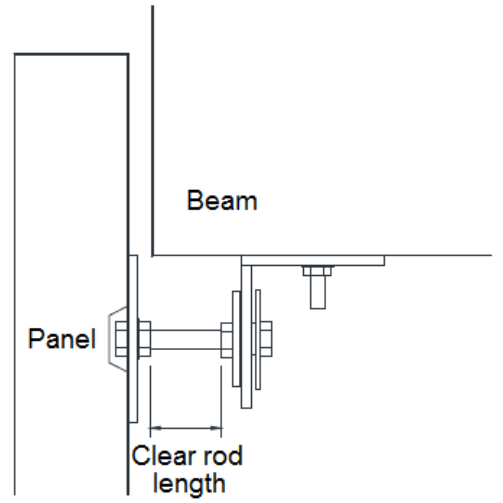

(b)

Figure 7: Detailing of precast concrete connections [17]; (a) slotted connections component detailing, and (b) side elevation of slotted connections. 
Table 9: Precast concrete cladding damage state descriptions.

\begin{tabular}{ccc} 
Damage state & Hunt and Stojadinovic [42] definition & Baird [17] definition \\
\hline 1 & Yielding of rod & Yielding of rod \\
2 & Rod ductility of 2 & $\begin{array}{c}\text { Cracks form parallel to the threads and occur } \\
\text { between threads }\end{array}$ \\
3 & Rod reached its maximum strength & $\begin{array}{c}\text { Cracks form perpendicular to threads, and parallel } \\
\text { cracks show noticeable prying } \\
4\end{array}$ \\
N/A & Failure of connections \\
\hline
\end{tabular}

Table 10: Existing fragility functions for precast concrete cladding (25 mm diameter rods with $200 \mathrm{~mm}$ ) in terms of lateral displacement between top and bottom connections.

\begin{tabular}{ccccc} 
Damage & \multicolumn{2}{c}{ Hunt and Stojadinovic [42] } & \multicolumn{2}{c}{ Baird [17] } \\
\cline { 2 - 5 } state & Median & Dispersion & Median & Dispersion \\
\hline 1 & $19 \mathrm{~mm}$ & 0.25 & $1.9 \mathrm{~mm}$ & 0.2 \\
2 & $31 \mathrm{~mm}$ & 0.25 & $5.8 \mathrm{~mm}$ & 0.2 \\
3 & $55 \mathrm{~mm}$ & 0.25 & $24 \mathrm{~mm}$ & 0.2 \\
4 & - & - & $38 \mathrm{~mm}$ & 0.2 \\
\hline
\end{tabular}

\section{Evaluation of Precast Concrete Cladding Fragility Functions}

As the fragility functions proposed by Baird [17] are based on detailing commonly used in New Zealand, and experimental results appear to have been reasonably well validated with numerical modelling, no major modifications are proposed here. The only suggestion is that the lateral displacements could be divided by the distance between the threaded rod connection and the base connection to determine the drifts which causes the onset of the corresponding damage state; though this assumes that rotation of the panel does not occur.

Comparison of the $200 \mathrm{~mm}$ threaded rod connection with 50 $\mathrm{mm}$ diameter is shown in Figure 8. It can be seen here that the fragility functions by Baird [17] indicate a significantly higher probability of failure compared to Hunt and Stojadinovic [42] for the threaded rod dimensions.

One method to evaluate which is more realistic would be to compare the yield displacements corresponding to damage state 1. The lateral yield displacement, $\Delta_{y}$, for the threaded rod can be approximated by Equation 2 assuming that the rod deforms in double curvature with equal moment demands at both ends and linearly varying moment demands in between.

$$
\Delta_{y}=\frac{f_{y} l_{r}{ }^{2}}{3 E d_{r}}
$$

where $f_{y}$ is the yield stress ( $300 \mathrm{MPa}$ ), $l_{r}$ is the rod length (200 $\mathrm{mm}), E$ is the Young's Modulus for steel $(200 \mathrm{GPa})$, and $d_{r}$ is the bar diameter $(25 \mathrm{~mm})$. Substituting these values into Equation 2 results in $\Delta_{y}=0.8 \mathrm{~mm}$. It can be seen that both Baird [17] and Hunt and Stojadinovic [42] predict higher lateral displacements corresponding to yield. This is likely due to flexibility of the plate connection which allows for an accommodation of additional displacement. However, the prediction by Hunt and Stojadinovic [42] $(19 \mathrm{~mm})$ is off by an order of magnitude. On further review, it is not clear how Hunt and Stojadinovic [42] interpreted the test results by McMullin et al. [43] to develop their fragility function. Based on this observation, the fragilities proposed by Baird [17] are recommended for use in New Zealand.

The potential relevance of precast panel fragility on the seismic performance of buildings will be highlighted using a case study examined later in this paper.

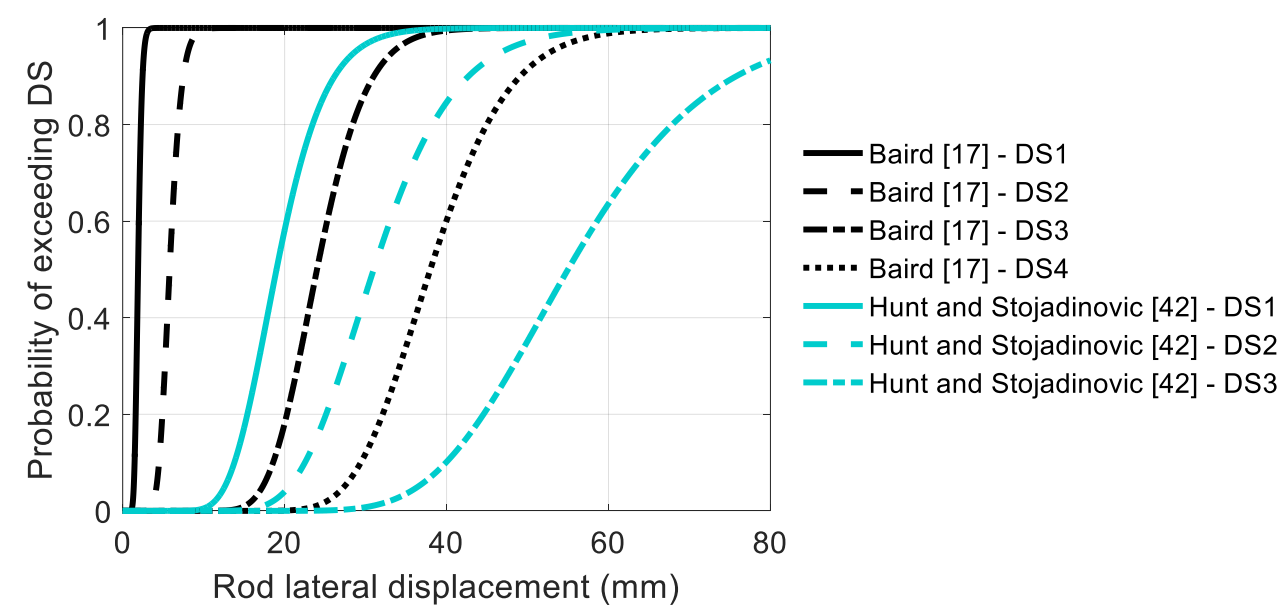

Figure 8: Evaluation of precast concrete cladding fragility function. 


\section{STEEL BEAM-COLUMNS WITH EXTENDED MOMENT END PLATES}

\section{Detailing of Steel Beam-Column Joints in New Zealand}

Beam-column connections used in steel moment-resisting frames are usually extended bolted end-plate connections, such as that shown in Figure 9a. In these joints, the beam is welded to an end-plate which is then bolted to the column. Tables containing pre-engineered extended bolted end-plate connections for a range of beam and column combinations available in New Zealand are provided by Hyland et al. [44]. It should be noted here that this detailing is very different to the welded connections commonly used in the US, where the beam flanges are welded directly to the column while the web is connected via a shear plate, as shown in Figure 9b.

\section{Existing Steel Beam-Column Joint Fragility Functions}

Three fragility functions for steel beam-column joints based on experimental data are examined here. The first is that by Deierlein and Victor [11] which is currently implemented in PACT [13]. The fragility functions are based on experimental testing of welded connections shown in Figure 9b, and as such are not directly relevant for New Zealand usage. However, at the time of writing, no fragilities are available in PACT [13] for extended bolted end-plate connections. Two sets of fragilities are provided by Deierlein and Victor [11], one where reduced beam sections (RBS) are used and the other without. 8 specimens from two experimental studies were considered for the case with RBS, while 27 specimens from five experimental studies were considered where RBS detailing was not used. All specimens considered had floor slabs included, as Deierlein and Victor [11] noted that local buckling and flexural lateral torsional buckling tended to occur earlier for specimens with RBS if the floor slab was not attached; though the slab effect on specimens without RBS is minor. The damage state definitions considered by Deierlein and Victor [11] are shown in Table 11. It should be noted that, according to Deierlein and Victor [11], DS2 is closely related to the peak capacity of the steel specimen.

The second set of fragility functions examined here are those proposed by Lignos et al. [46]. These fragilities were also based on welded connections and are also not directly relevant for New Zealand usage. The study focused only on RBS sections, and included specimens with and without floor slab effects in its derivation. 71 specimens were collected from fourteen experiment studies, including the two studies also considered by Deierlein and Victor [11]. The damage state definitions considered here are also shown in Table 11.

The final set of fragility functions examined here are those provided by Roldan et al. [47] which are based on 40 extended moment-end-plate connections from a dataset adapted from Della Corte et al. [48]. The damage state definitions considered here are also shown in Table 11. The fragility functions from the three sources described are shown in Table 12.

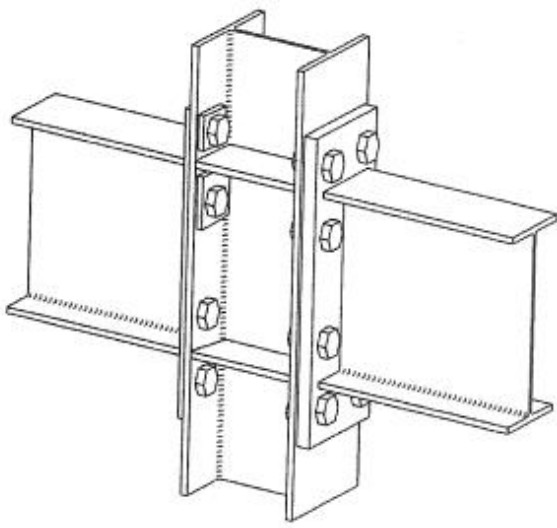

(a)

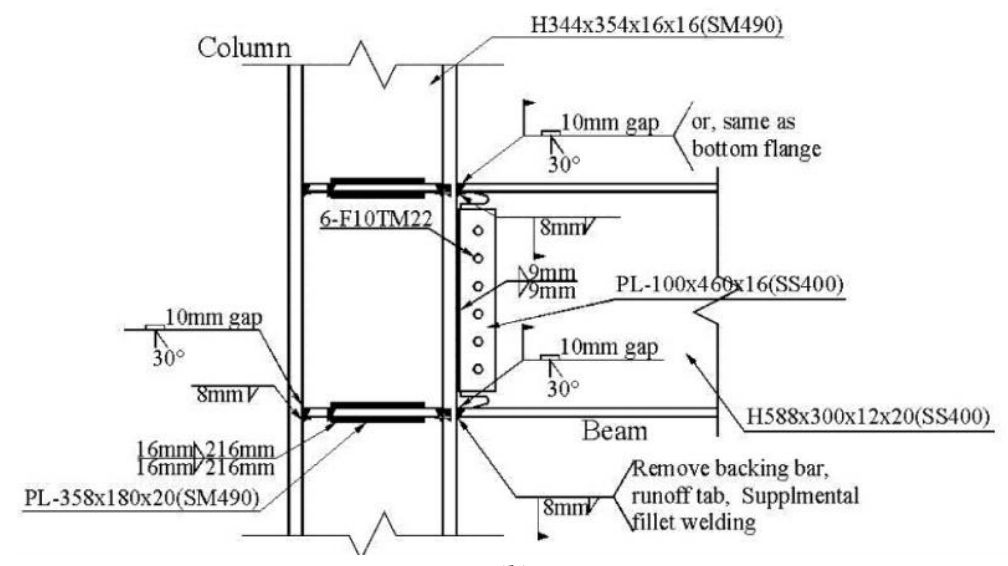

(b)

Figure 9: Typical beam-column connections in steel frames; (a) extended end-plate commonly used in New Zealand [44], and (b) example of welded connection commonly used in US tested by Han et al. [45].

Table 11: Damage state descriptions found in literature for steel beam-column assemblies.

\begin{tabular}{cccc} 
Damage states & Deierlein and Victor [11] & Lignos et al. [46] & Roldan et al. [47] \\
\hline 1 & $\begin{array}{c}\text { Local beam flange and web } \\
\text { buckling }\end{array}$ & $\begin{array}{c}\text { Yielding anywhere (i.e. beam or panel } \\
\text { zone) }\end{array}$ & $\begin{array}{c}\text { Plastic moment capacity is } \\
\text { developed }\end{array}$ \\
2 & $\begin{array}{c}\text { DS1 with lateral-torsional } \\
\text { distortion in hinge region }\end{array}$ & $\begin{array}{c}\text { Local buckling at top or/and bottom } \\
\text { flanges or web of beam }\end{array}$ & $\begin{array}{c}\text { Joint resistance falls below its } \\
\text { plastic moment capacity }\end{array}$ \\
3 & Low-cycle fatigue fracture & First occurrence of fracture & N/A \\
\hline
\end{tabular}

Table 12: Existing fragility functions for steel beam-column assemblies using reduced beam sections based on peak interstorey drift.

\begin{tabular}{ccccccc} 
Damage & \multicolumn{2}{c}{ Deierlein and Victor [11] } & \multicolumn{2}{c}{ Lignos et al. [46] } & \multicolumn{2}{c}{ Roldan et al. [47] } \\
\cline { 2 - 7 } state & $\boldsymbol{x}_{\boldsymbol{m}}$ & $\boldsymbol{\beta}$ & $\boldsymbol{x}_{\boldsymbol{m}}$ & $\boldsymbol{\beta}$ & $\boldsymbol{x}_{\boldsymbol{m}}$ & $\boldsymbol{\beta}$ \\
\hline 1 & 0.030 & 0.3 & 0.010 & 0.17 & 0.008 & 0.45 \\
2 & 0.040 & 0.3 & 0.022 & 0.30 & 0.038 & 0.47 \\
3 & 0.050 & 0.3 & 0.050 & 0.31 & & $\mathrm{~N} / \mathrm{A}$ \\
\hline
\end{tabular}


In addition to the three experimental data-based fragility functions, a mechanics-based approach to develop fragility functions had been proposed by Roldan [49] following the same damage state definition as Roldan et al. [47]. This is based on relationships between drifts and beam rotation proposed by Della Corte et al. [48] and Roldan et al. [50] shown in Figure 10 , where $\theta_{y}$ is the drift at yield rotation of the beam, $\theta_{p}$ is the inelastic rotation of the beam, and $\theta_{S C}$ is the resulting total drift.

Della Corte et al. [48] and Roldan et al. [50] proposed to calculate $\theta_{y}$ following Equation 3 .

$\theta_{y}=\frac{M_{j, R} \cdot L_{b}}{6 \cdot E \cdot I_{b}}\left(1+6 \frac{E \cdot I_{b}}{S_{j, \text { ini }} \cdot L_{b}}+\frac{1}{2} \frac{\beta \cdot I_{b} \cdot H}{I_{c} \cdot L_{b}}\right)$

where $M_{j, R}$ is the moment capacity of the joint; $E$ is the Young's modulus of steel; $I_{b}$ and $I_{c}$ are the moment of inertia of the beam and column, respectively; $L_{b}$ is the length of the beam; $H$ is the height between adjacent column points of infliction; $\beta$ is 1.0 and 2.0 for external and internal joints, respectively; and $S_{j, \text { ini }}$ is the initial stiffness of the entire joint subassembly. $M_{j, R}$ is taken as the minimum of (i) the plastic moment of the beam cross section, (ii) the plastic resistance of the beam-to-column connection, (iii) the beam end moment corresponding to the plastic shear resistance of the column web, and (iv) the beam end moment corresponding to the plastic resistance of the column cross section. There are several methods available to calculate $S_{j, i n i}$, such as adopting the component method approach from Eurocode 3 [51], or a simplified empirical approach by Della Corte et al. [48] for cases where one beam frames into the joint.

In between damage states 1 and 2 , all additional drift is assumed to be taken up by the plastic hinge in the beam, $\theta_{p}$. Considering experimental observations, Roldan [49] proposed that the distribution of $\theta_{p}$ which triggers damage state 2 can be defined by normal distribution with a mean of $44.4 \mathrm{mrad}$ and a standard deviation of $20.3 \mathrm{mrad}$. This can be directly added onto the drift corresponding to yield rotation obtained from Equation 3 to obtain $\theta_{S C}$ at damage state 2 . The advantage of this mechanics- based approach is that it can be easily tailored to suit the beamcolumn joint configuration of interest; such as different beam and column sections and lengths, plate thicknesses, steel grades, among others. In contrast, the other fragility functions proposed are more generic which might not be applicable to a wide range of cases.

\section{Modifications for Moment-End-Plate Connections to Address Reduced Beam Section Effects}

Out of the fragility function options discussed, the mechanicsbased approach will be considered further as it can be easily applied for New Zealand sections and connection detailing. One modification which can be made to this approach, however, is to allow for the consideration of reduced beam sections. This will have three effects; (i) the reduced capacity of the beam section needs to also be considered in obtaining $M_{j, R}$, (ii) the effective stiffness of the beam had decreased due to the reduced section, and (iii) the location of the plastic hinge will have shifted from the column face, and as such the additional drifts are not equal to the rotation of the plastic hinge.

The reduced beam stiffness can be approximated by using an effective moment of inertia, $I_{b e f f}$, instead of $I_{b}$. This can be done by modelling the reduced beam section as a simply supported beam, applying moments on both ends of the beam identical in size and direction, and then calculating the rotation at the beam ends. An equivalent prismatic beam with $I_{\text {beff }}$ can then be obtained so that the same rotations are obtained for the same loading.

The plastic hinge location effect can be approximated by considering the geometry of the frame deformed shape shown in Figure 11. Based on this, the plastic rotation demand on the beam, $\theta_{p, \text { beam }}$, due to additional drifts on the column past the point of yielding, $\theta_{p, c o l}$, can be approximated as shown in Equation 4.

$$
\theta_{p, \text { beam }}=\frac{\theta_{p, c o l} \cdot L_{b}}{L_{b}-2 L_{c e n}}
$$

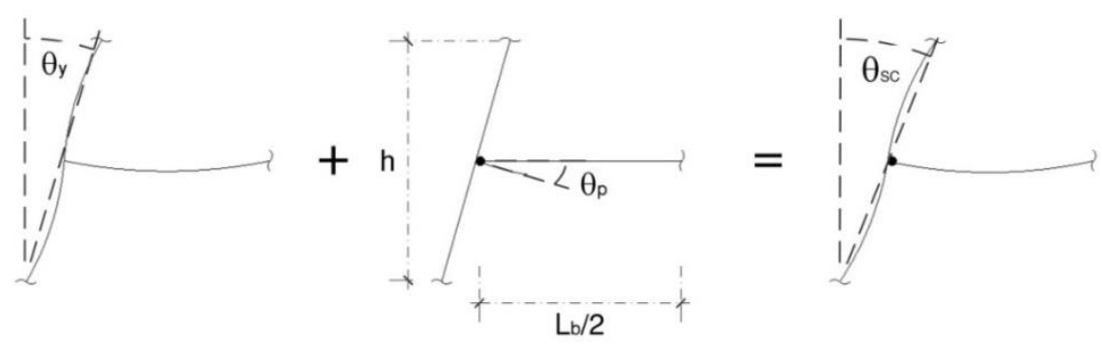

Figure 10: Interstorey drift capacity for external beam-to-column subassembly [50].

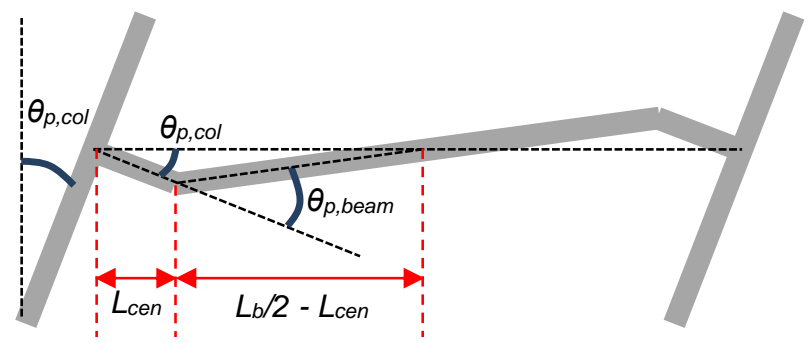

Figure 11: Relation between column drift and beam plastic rotation for beam-column joints with reduced beam sections. 
where $L_{c e n}$ is the location of the reduced beam section centroid from the column face. The plastic rotation which the beam can take before reaching its peak strength capacity is assumed to be defined by a normal distribution with a mean of $44.4 \mathrm{mrad}$ and a standard deviation of $20.3 \mathrm{mrad}$ following Roldan [49].

In the absence of information regarding the probabilistic distribution of several variables such as yield strength and Young's modulus, the "Derived Fragility" approach proposed by Porter et al. [18] is used. Note that if the probabilistic distributions are known, a Monte Carlo simulation approach can be adopted instead, though it will be more complicated to adopt in practice. The steps are as follows:

1. Calculate $\theta_{y}$ for the frame configuration following Equation 3 using $I_{b e f f}$ instead of $I_{b}$.

2. Calculate $\theta_{S C}$ assuming $\theta_{p, \text { beam }}=44.4 \mathrm{mrad}$ and calculating $\theta_{p, c o l}$ by rearranging Equation 4 .

3. Multiply $\theta_{y}$ and $\theta_{S C}$ by 0.92 to obtain the median drift which triggers DS1 and DS2, respectively, and assume a dispersion of 0.4 following Porter et al. [18].

\section{Evaluation on the Importance of Slab Effect for Reduced Beam Section Beams}

One of the limitations of the approach adopted is that the effect of floor slabs had not been incorporated into derivation approach. To test the importance of slab effects, the dataset of the 71 specimens considered by Lignos et al. [46] is examined in more detail. The first step is to split the data into two groups, one for specimens with slabs included and the other without. The "Actual Failure EDP" approach was then performed to derive the fragility for each set which is shown in Figure 12a. It can be seen that there is significant differences between the two sets, particularly for DS3.

On the surface, this result validates Deierlein and Victor [11] use of only specimens where the slab effect was included. However, a number of experimental programs considered by Lignos et al. [46] had only tested specimens without floor slabs. The fragility functions were recalculated considering only samples from experimental studies which tested both specimens with and without floor slabs, and are shown in Figure 12b. It can be seen that there is still a noticeable difference at damage state 3. However, this difference is not as large as observed previously. Furthermore, damage state 3 was triggered at drifts greater than 0.05 for all cases, and the small dispersion for the case without slabs is likely due to there being only three specimens in this category with information on the onset of damage state 3 . This indicates that the large difference in fragilities might not necessarily only be attributed to the floor slab effect, but could also likely due to different experimental conditions. Based on this observation, it is deemed that while consideration of floor slabs may have an effect on fragilities, for the purposes of this study this effect is not as significant and can be ignored.

\section{Evaluation of Steel Beam-Column Fragility Functions}

To test the various fragility functions, an $8 \mathrm{~m}$ long 610UB101 beam with a reduced beam section $(40 \%$ reduction in width at the narrowest portion) and a $3.6 \mathrm{~m}$ tall $900 \mathrm{WB} 175$ column configuration are considered. The joint properties are as shown in Table 13. Note that the simplified empirical approach by Della Corte et al. [48] was used to calculate $S_{j, i n i}$ for the comparisons.

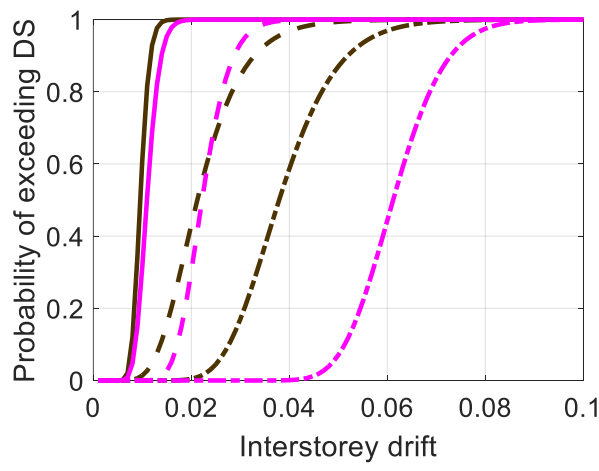

(a)

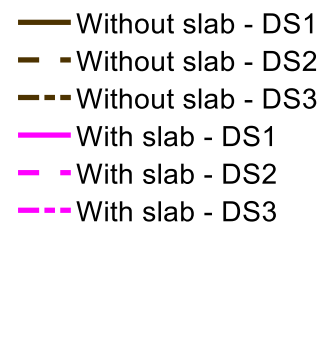

---Without slab - DS3

-With slab - DS1

- - With slab - DS2

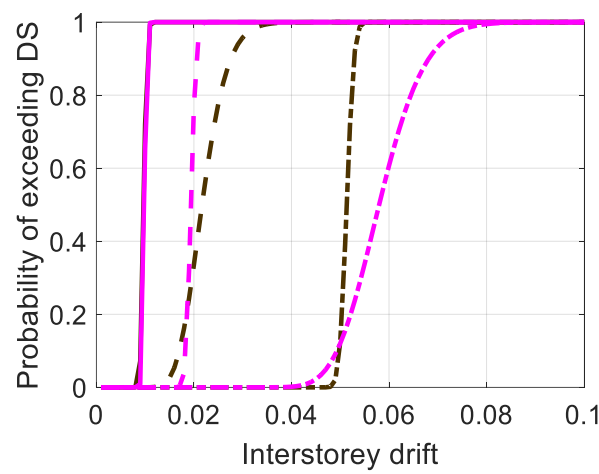

(b)

Figure 12: Effect of floor slabs on fragility functions from Lignos et al. [46]; (a) all tests considered, and (b) excluding experiment studies which only performed tests without slabs [excluding tests 28-29 due to exceptionally early onset of DS2].

Table 13: Properties for example steel frame fragility function.

\begin{tabular}{ccc} 
Variable & Description & Value \\
\hline$F_{y, b}$ & Yield strength of beam flanges & $300 \mathrm{MPa}$ \\
$Z_{e x, b}$ & Effective beam section modulus & $2.12 \times 10^{6} \mathrm{~mm}^{3}$ \\
$l_{b e f f}$ & Beam moment of inertia & $7.22 \times 10^{8} \mathrm{~mm}^{4}$ \\
$h_{b}$ & Beam depth & $602 \mathrm{~mm}$ \\
$L_{b}$ & Beam length & $8000 \mathrm{~mm}$ \\
$L_{c e n}$ & Hinge centroid location & $310 \mathrm{~mm}$ \\
$t f c$ & Column flange thickness & $20 \mathrm{~mm}$ \\
$I_{c}$ & Column moment of inertia & $2.96 \times 10^{9} \mathrm{~m}$ \\
$h_{c}$ & Column depth & $900 \mathrm{~m}$ \\
$H$ & Column height & $3600 \mathrm{~m}$ \\
$E$ & Young's modulus & $200 \mathrm{GPa}$ \\
$d$ & Bolt diameter & $30 \mathrm{~mm}$ \\
\hline
\end{tabular}


The comparisons between the derived fragility function against those available in literature are shown in Figure 13. Only the damage states related to yielding or the onset of strength degradation were considered. Further damage states were not considered as the costs associated with repair actions of higher levels of damage is similar to that of damage state 2. It can be seen that the fragility derived from the adopted approach predicts higher probability of yielding at lower levels of interstorey drift. One reason for this is that the beam and column sizes considered in this derivation approach is considerably larger than the experimental specimens considered in literature for deriving fragility functions, resulting in a stiffer joint which yields at a lower drift.

One interesting observation, however, is that the median interstorey drift corresponding to DS2 is $8-14 \%$ larger for the adopted approach compared to that from Roldan et al. [47] and Deierlein and Victor [11]. The former is despite the opposite being true at DS1. Both the fragility functions and the plastic rotation mean considered of $44.4 \mathrm{mrad}$ by Roldan et al. [47] are based off the dataset from Della Corte et al. [48], which indicates that there is potential inconsistency in Roldan et al. [47]. Differences with Deierlein and Victor [11] could be due to the plastic rotation capacity being smaller for RBS sections than for non-RBS sections.

The largest difference observed for DS2 is between Lignos et al. [46] and the adopted approach. One reason for this could be that DS2 for Lignos et al. [46] includes local buckling of the beam's web, which generally occurs before buckling of the beam flanges, the latter of which is when the strength starts to deteriorate according to Deierlein and Victor [11]. As such, DS2 for Lignos et al. [46] is likely to be indicative of lesser damage and is therefore on the conservative side.

Based on these observations, it is not clear whether Roldan et al. [47] or the approach adopted is more "accurate". However, as the adopted approach has the flexibility to consider a wider range of frame configurations, it is deemed to be more useful for engineering practice. The other two fragility functions are not ideal since those are based off connection detailing which is not reflective of New Zealand practice.

\section{IMPORTANCE OF FRAGILITY FUNCTION SELECTION ON SEISMIC LOSSES}

\section{Case Study Details}

As discussed in the introduction, one of the objectives of this paper is to assess the impact fragility functions have on the computed losses from a seismic loss estimation case study. The case study building considered is a 4-storey steel momentresisting frame building located on Wellington subsoil class $\mathrm{C}$ conditions which was designed and analysed in a loss estimation study by Yeow et al. [52]. It should be noted here that this building may not be representative of most steel buildings currently being constructed in Christchurch following the 2010-11 Canterbury earthquakes where braced frames are more commonly used. Nonetheless still useful in highlighting potential differences in seismic losses arising from adopting different fragility functions. The building has a replacement cost of $\$ 8.22$ million, and the general layout of the building, the building's collapse fragility, and the drift and acceleration response in $50 \%$ and $10 \%$ probability of exceedance ground motion shaking are shown in Figure 14

A full building inventory with repair/replacement costs provided for each building component had been considered by Yeow et al. [52], including partial-height partitions, glazing, stairs, elevators, and services in addition to the other building components considered in this study; the details of which are available on the QuakeCoRE wiki page (see acknowledgements). The repair costs adopted for partitions and ceilings were taken from Dhakal et al. [53], which is based on data obtained from a survey of New Zealand practitioners, while the repair cost of cladding was sourced from Baird [17]. Repair costs for steel components based on New Zealand research were not readily available in literature. However, since the purpose of this assessment is to investigate the relative difference in assessed losses from the different fragility options, cost values were adopted from Lignos et al. [46], which is based on US practice, converted to New Zealand dollars. These costs include all monetary losses involved with repair work, but not the effect of building usage disruptions on operational costs and income.

In this comparison, seismic loss estimation is performed considering all of the different fragility functions alternatives examined for the range of building components considered in this study (i.e. interior full-height steel-framed partitions, unbraced suspended fixed-floating ceilings, precast concrete cladding, and extended end-plate steel beam-column joints). Note that for fair comparisons, the ceiling area categories and the precast panel connection details of the adopted approaches are to match those of the other sources (e.g. the ceiling area classification size is that from Table 5). The fragility functions considered for other building components were adopted from PACT [13]. The seismic loss estimation analyses were performed on the Seismic Loss Assessment Tool, SLAT [12].

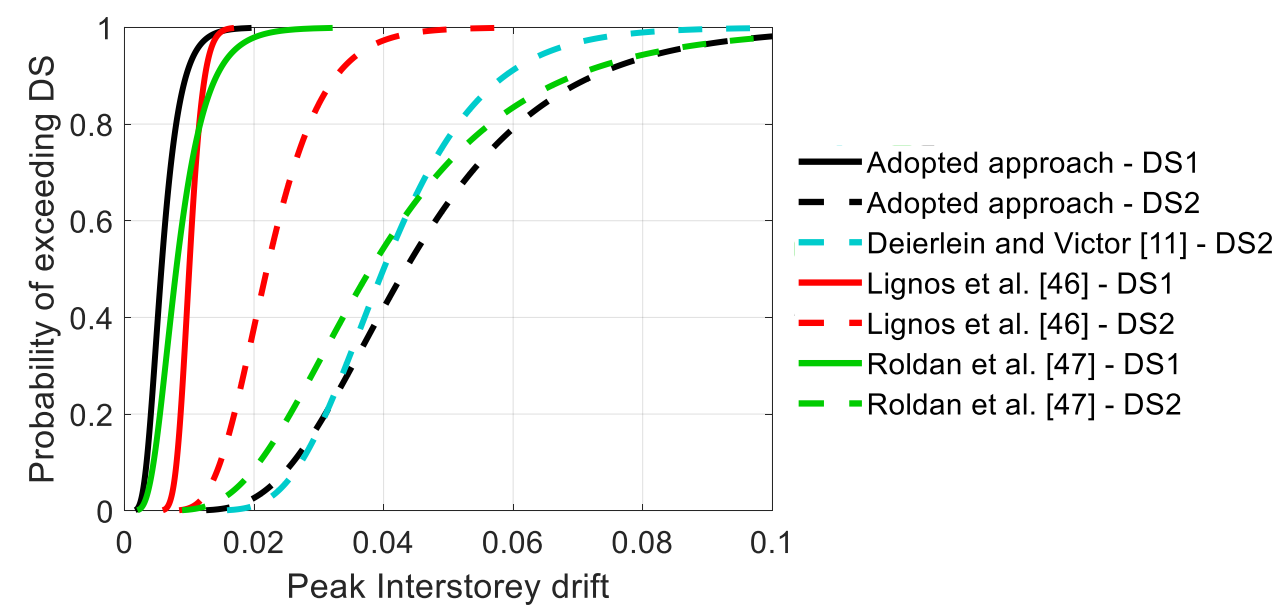

Figure 13: Relation between column drift and beam plastic rotation for beam-column joints with reduced beam sections. 


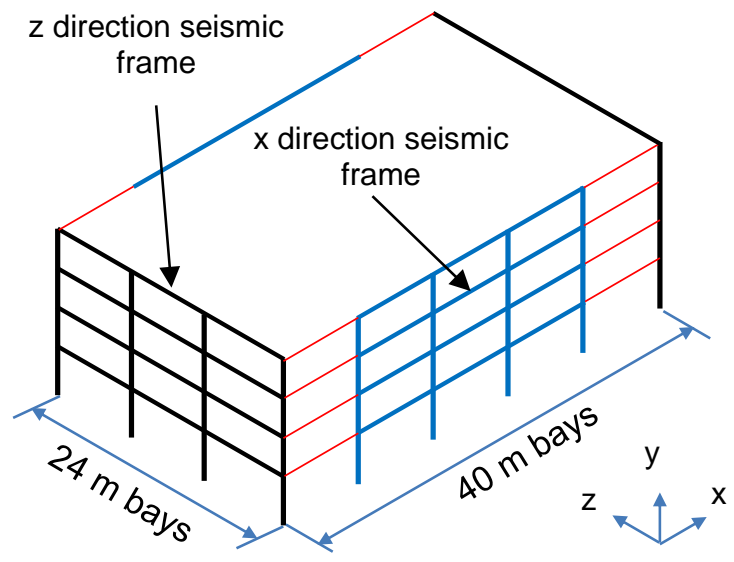

(a)

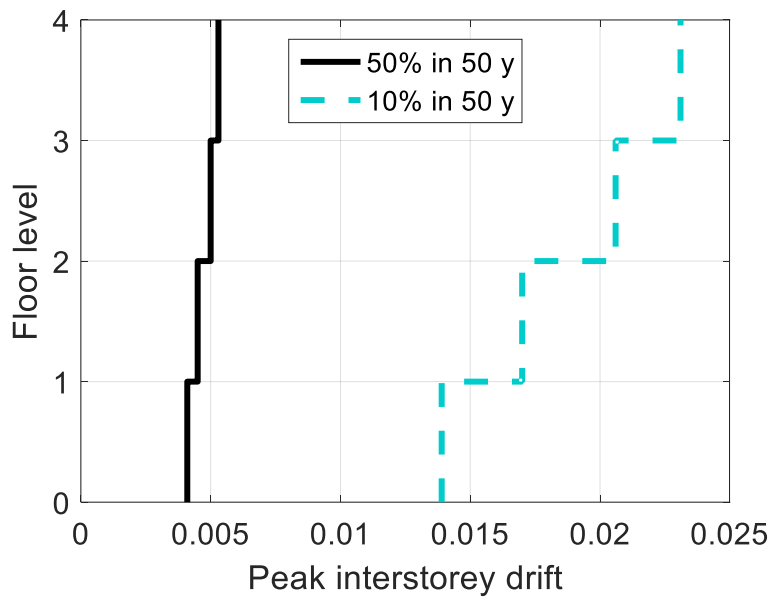

(c)

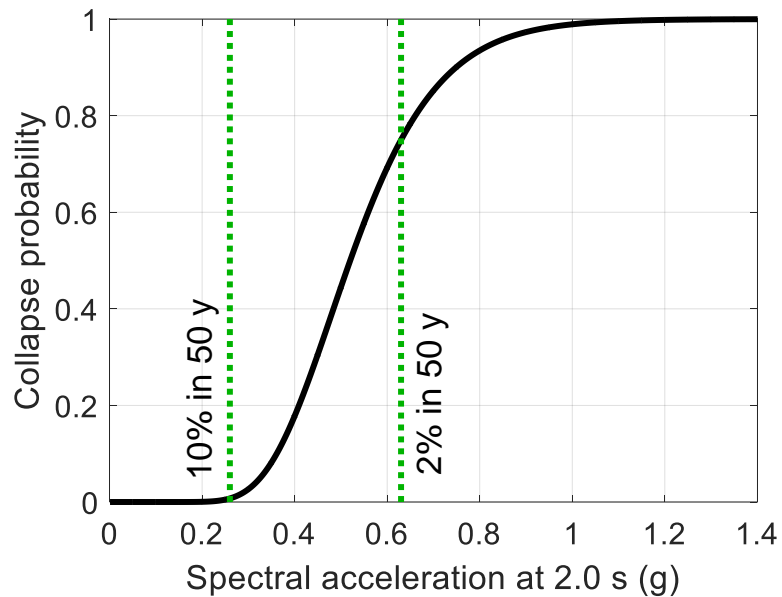

(b)

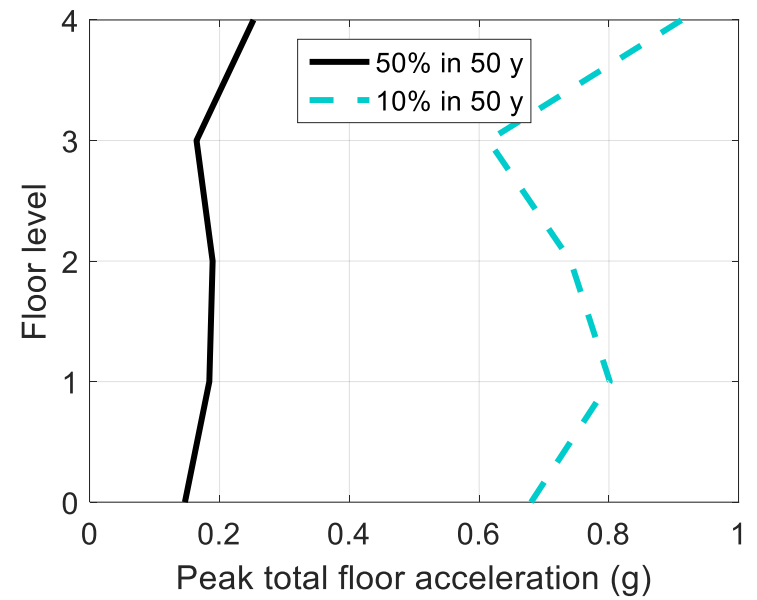

(d)

Figure 14: Building case study details; (a) building layout, (b) collapse fragility, (c) peak interstorey drift profiles, and (d) peak total floor acceleration profiles [52].

Two outputs will be examined in particular. The first is the expected repair cost of each component versus shaking intensity, $E\left[L_{\text {component }} \mid I M\right]$. This has accounted for the probability of building collapse, $P[C \mid I M]$, from Figure 14b following Equation 5.

$$
E\left[L_{\text {component }} \mid I M\right]=E\left[L_{\text {component }} \mid I M, N C\right] .(1-P[C \mid I M])
$$

where $E\left[L_{\text {component }} \mid I M, N C\right]$ is the expected repair cost of each component versus shaking intensity provided collapse did not occur. $E\left[L_{\text {component }} \mid I M, N C\right]$ can be extracted from SLAT [12] directly, and $E\left[L_{\text {component }} \mid I M\right]$ is then computed manually.

The second output examined is the expected annual repair cost of each component. This can be directly extracted from SLAT [12], though equations to derive this can be found in literature (e.g. Bradley et al. [7]).

\section{Expected Component Repair Cost Versus Shaking Intensity Comparisons}

The expected loss versus shaking intensity results, $E\left[L_{\text {component }} \mid I M\right]$, for each of the building components considered are shown in Figure 15. It can be seen that in all cases the expected loss eventually starts decreasing as the shaking intensity increases. This is because of the increase in collapse probability, particularly after a shaking intensity equivalent to a $10 \%$ in 50 year event as shown in Figure 14b.

For the interior full-height steel-frame partition walls shown in Figure $15 \mathrm{a}$, the results using the adopted approach closely matches that from Mosqueda [22]. This is as expected since these fragility functions are almost identical. In contrast, using the fragility from Miranda and Mosqueda [21] results in losses occurring earlier, and is due to the conservatism in the definition of the various damage state levels.

From Figure 15b, the unbraced fixed-floating suspended ceiling losses obtained using the fragility from Soroushian et al. [36] incurred the highest losses, followed by the adopted approach, then by Soroushian [37]. One reason for this is that two thirds of the unbraced suspended ceilings in the case study building falls within the lowest area size category, while the remainder falls within the second lowest. It can be seen from Figure 6a that the fragility from Soroushian et al. [36] predicts a higher probability of failure at lower accelerations for the smallest ceiling category due to its larger dispersion. Furthermore, it also considers more damage states which occur even earlier, and hence losses start incurring at lower accelerations. While Soroushian [37] also considers more damage states, the accelerations triggering these damage states are much higher, especially for larger ceiling sizes, which results in reduced repair costs compared to Soroushian et al. [36] and the adopted approach.

The precast concrete panel comparison in Figure $15 \mathrm{c}$ shows that losses occurs earlier for the fragility function provided by Baird [17]. As discussed earlier, this could be due to possible inconsistency in the fragility by Hunt and Stojadinovic [42], where the yield displacement of the threaded rod is a magnitude greater than that calculated from first principles. 
Finally, Figure $15 \mathrm{~d}$ shows that using the adopted approach for steel beam-column joints resulted in higher losses at lower shaking intensity. This is consistent with previous findings and is likely due to the stiffer sections used in the frame versus those considered in the derivation of the other three fragility functions. Eventually and interestingly, however, the losses from the adopted approach become the lowest of those considered. This is because (i) the final damage state was calculated to occur later than that found by Roldan et al. [47] and Deierlein and Victor [11], and (ii) the fragility function for DS2 by Lignos et al. [46] is conservative.

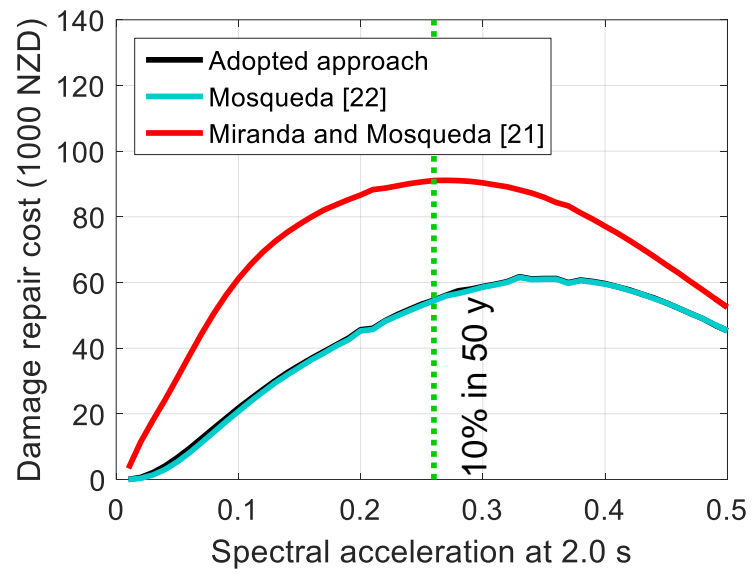

(a)

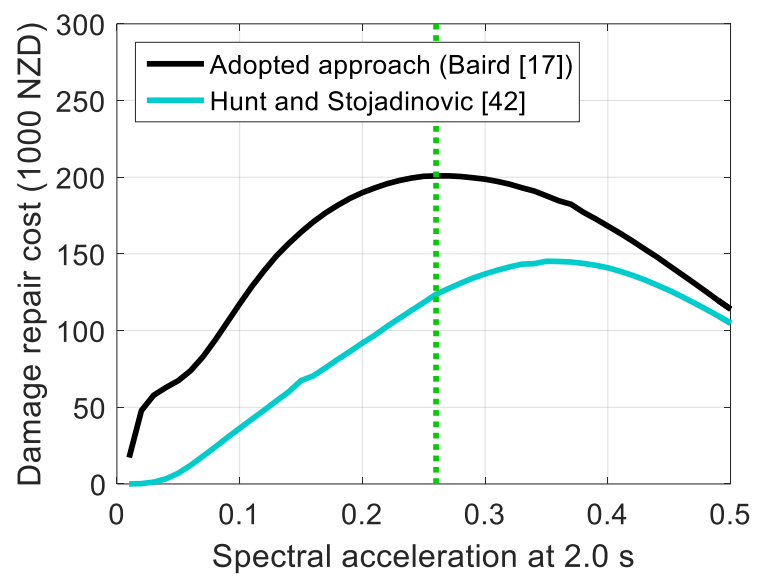

(c)

\section{Expected Annual Component Repair Cost Comparisons}

The expected annual repair cost for each component is shown in Table 14. It can be seen there that while there are still some large relative differences (i.e. the cladding expected annual loss considering the adopted approach is 5.6 times that of Hunt and Stojadinovic [42]), the size of these expected annual losses are small compared to the full replacement cost (range of less than $0.001 \%$ to $0.034 \%$ of total replacement cost). This is likely due to the fact that other building components which fragility functions were not examined in this study do make up a large component of the total replacement cost, and the expected annual repair cost for these other components are also large in comparison $(0.152 \%$ of full replacement cost $)$.

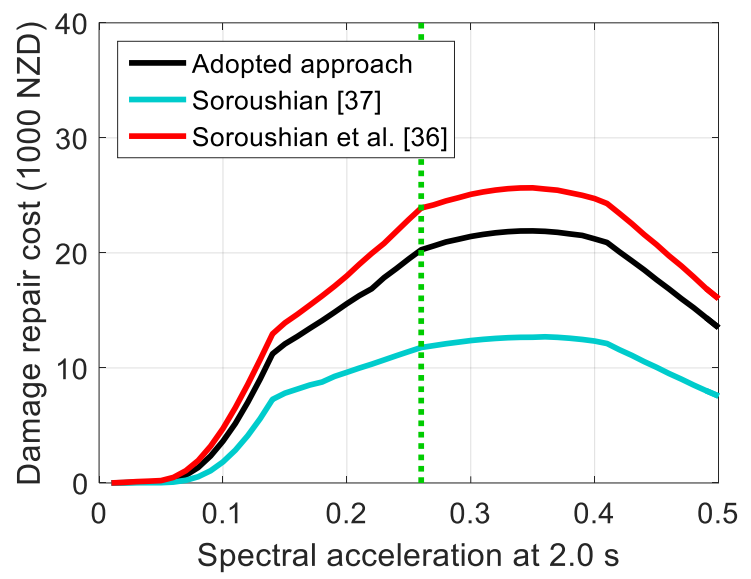

(b)

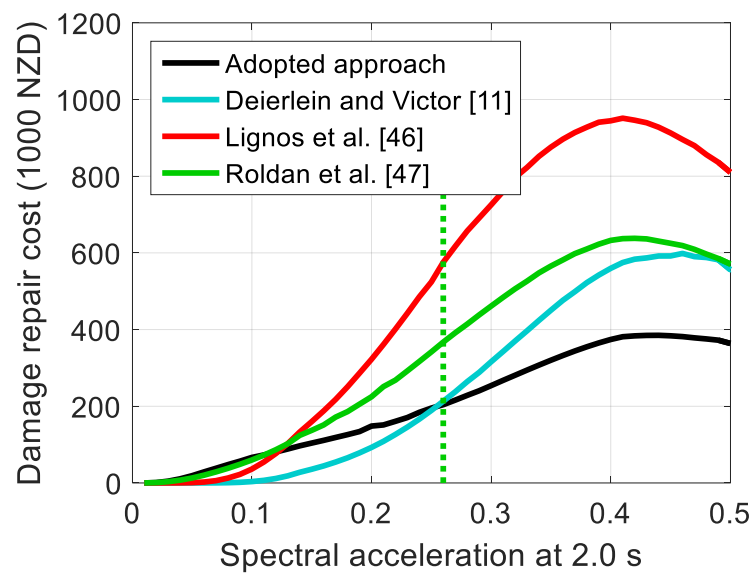

(d)

Figure 15: Expected repair cost of building components versus shaking intensity for case study building; (a) partitions, (b) ceilings, (c) precast concrete cladding, and (d) steel beam-column joints.

Table 14: Expected annual component repair cost in NZD.

\begin{tabular}{|c|c|c|c|c|}
\hline Component & Adopted & Alternative 1 & Alternative 2 & Alternative 3 \\
\hline Partitions & 295 (0.004\%) & $\begin{array}{c}273(0.003 \%) \\
\text { (Mosqueda [22]) }\end{array}$ & $\begin{array}{l}1030(0.013 \%) \\
\text { (Miranda and } \\
\text { Mosqueda [21]) }\end{array}$ & - \\
\hline Ceilings & $65.8(0.001 \%)$ & $\begin{array}{c}37.8(0.000 \%) \\
\text { (Soroushian et al. [36]) }\end{array}$ & $\begin{array}{c}78.4(0.001 \%) \\
\text { (Soroushian [37]) }\end{array}$ & - \\
\hline Cladding & $2770(0.034 \%)$ & $\begin{array}{c}507 \text { (0.006\%) } \\
\text { (Hunt and Stojadinovic [42]) }\end{array}$ & - & - \\
\hline Steel BC & $1070(0.013 \%)$ & $\begin{array}{l}738(0.009 \%) \\
\text { (Deierlein and Victor [11]) }\end{array}$ & $\begin{array}{c}1670(0.020 \%) \\
\text { (Lignos et al. [46]) }\end{array}$ & $\begin{array}{c}1390(0.017 \%) \\
\text { (Roldan et al. [47]) }\end{array}$ \\
\hline $\begin{array}{l}\text { Others (including } \\
\text { collapse loses) }\end{array}$ & & $12,500(0$ & & \\
\hline
\end{tabular}

* values in brackets are expected losses expressed as a percentage of building replacement cost. 


\section{DISCUSSION}

\section{Implications of Findings}

The results shown in Table 14 can be interpreted in two different ways. Firstly, large relative differences can be observed for some components, such as for partitions where the adopted approach predicted an expected annual component repair cost $61 \%$ lower than that from Miranda and Mosqueda [21]. This highlights the importance of careful selection of fragility functions, particularly where it is important to assess the performance of each category of building components.

Another view is that the difference in observed expected annual repair cost for each component is small relative to the building's replacement value. This indicates that the selection of fragility functions may not drastically alter the outcome of cost-benefit assessments using the computed expected annual loss value. One implication of this is that, in cases where no fragility functions have been identified as being suitable for use in New Zealand, perhaps fragility functions readily available on PACT [13] can be adopted for convenience and yet still provide reasonable predictions. Nonetheless, it is still best to use fragility functions which are relevant to New Zealand practice where possible.

\section{Possible Improvements to Adopted Fragility Functions}

One of the biggest differences observed in the repair cost versus shaking intensity results from Figure 15 is due to some of the adopted fragility functions not considering earlier damage states; such as the adopted ceiling fragility function not considering a partial damage state where full replacement is not required. Other possible improvements which could be made includes (i) deriving more generic fragility functions for precast cladding and steel beam-column sections for easier adaption in engineering practice, (ii) introducing random variables for developing the steel beam-column joint fragility function, particularly for steel material properties such as yield strength and Young's modulus, rather than following the simplified "Derived Fragility" approach from Porter et al. [54], and (iii) performing additional experimental tests for these components using detailing typical of New Zealand practice to create a more thorough database to develop higher quality fragility functions. Several studies have been planned or are underway to address the latter $[55,56]$.

\section{Consideration of Other Building Components}

Due to the wide range of building components which exist in a building, this study had limited the scope to just four building components which had either been observed to incur extensive damage in past events or are present in a large proportion of building stock in Christchurch. However, there are a wide range of other building components which had not been included, such as other types of partitions (partial-height and/or timberframed), braced ceilings, other types of cladding, flooring systems, stairs, elevators, and overhead services. Of particular importance for immediate future work should be the components which significantly compromise the integrity of the building if damaged. In discussion with practitioners, this includes transformers which may be financially unfeasible to repair if significantly damaged during an earthquake, and sprinklers which can cause heavy flooding damage.

\section{CONCLUSIONS}

Existing fragility functions from literature are reviewed in this study to assess their relevance and applicability for use in New Zealand practice. Modifications to these fragility functions, if needed, were made where possible. The resulting fragility functions adopted are as follows:
- $\quad$ Partitions - the fragility functions proposed by Mosqueda [22] was modified by considering more specimens from experimental programs not previously included (see Table $3)$.

- Ceilings - the approach by Dhakal et al. [32] was modified by incorporating relationships linking peak total floor acceleration to peak total ceiling acceleration, and generalizing it based on typical distribution of ceiling sizes (see Table 8).

- $\quad$ Precast cladding - the fragility functions were adopted straight from Baird [17].

- Steel beam-column assemblies - the fragility derivation approach by Roldan [49] was modified to consider the possible effect of using reduced beam sections.

A loss estimation case study was performed to investigate the significance of fragility function selection on seismic losses. It was found that this had an effect on the damage repair costs incurred for each individual component type. However, the significance of this on the expected annual loss is minor (i.e. far less than $0.1 \%$ of the building's replacement value for each component type). It is recommended that fragility functions for building components with similar detailing to that used in New Zealand be used where available, and that other readily available fragility functions can be used as placeholders where there is an absence for such which are relevant for use in New Zealand.

\section{ACKNOWLEDGEMENTS}

This project was supported by QuakeCoRE, a New Zealand Tertiary Education Commission-funded Centre. This is QuakeCoRE publication number 0279. The authors would also like to acknowledge Ali Sahin Tasligedik, Rajesh Dhakal, Atefeh Pourali, and Andrew Baird for their advice on detailing of various non-structural elements. The authors would also like to thank the reviewers of this paper for their helpful comments, alternative reasoning for several observations, and their insightful discussions.

Information on ground motion records and building components (quantity, fragility, and consequence functions) are available at the following link:

https://wiki.canterbury.ac.nz/display/QuakeCore/Project+17137++Usage+of+Seismic+Loss+Assessment+to+Motivate+High+Performa $\underline{\text { nce }+ \text { Building }+ \text { Solutions }}$

\section{REFERENCES}

1. Dhakal RP (2010). "Damage to non-structural components and contents in 2010 Darfield Earthquake". Bulletin of the New Zealand Society for Earthquake Engineering, 43(3): 404-411.

2. Dhakal RP, MacRae G and Hogg K (2011). "Performance of ceilings in the February 2011 Christchurch Earthquake". Bulletin of the New Zealand Society for Earthquake Engineering, 44(4): 377-387.

3. Baird A, Palermo A and Pampanin S (2011). "Facade damage assessment of multi-storey buildings in the 2011 Christchurch earthquake". Bulletin of the New Zealand Society for Earthquake Engineering, 44(4): 368-376.

4. Yeow TZ, Baird A and Ferner H (2017). "Which building components caused injuries in recent New Zealand earthquakes?". Proceedings of the 2017 NZSEE Conference, Wellington, NZ.

5. Aslani H and Miranda E (2005). "Probabilistic Earthquake Loss Estimation and Loss Disaggregation in Buildings". The John A Blume Earthquake Engineering Center - Report No. 157, Department of Civil and Environmental Engineering, Stanford University, 383 pp. 
6. Mitrani-Reiser J (2007). "An Ounce of Prevention: Probabilistic Loss Estimation for Performance Based Earthquake Design". PhD Dissertation, California Institute of Technology, $383 \mathrm{pp}$.

7. Bradley BA, Dhakal RP, Cubrinovski M, MacRae GA and Lee DS (2009). "Seismic Loss Estimation for Efficient Decision Making". Bulletin of the New Zealand Society for Earthquake Engineering, 42(2): 96-110.

8. Yeow TZ (2017). "Building-Specific Seismic Resilience Assessment Frameworks Considering Content Sliding Injury". PhD Dissertation, University of Canterbury, 324 pp.

9. Standards New Zealand (2004). "NZS 1170.5:2004 Structural Design Actions Part 5: Earthquake Actions New Zealand (Commentary)". Standards New Zealand, Wellington, New Zealand.

10. Deierlein GG, Krawinkler H and Cornell CA (2003). "A Framework for Performance-based Earthquake Engineering". Proceedings of the 2003 Pacific Conference on Earthquake Engineering, Christchurch, New Zealand.

11. Deierlein GG and Victor V (2008). "Fragility Curves for Components of Steel SMR Systems". Background Document FEMA P-58/BD-3.8.3, Applied Technology Council, Redwood City, CA, 62 pp.

12. Bradley BA (2011). "SLAT: Seismic Loss Assessment Tool (Version 1.16)". Department of Civil and Natural Resources Engineering, University of Canterbury, Christchurch.

13. Naeim F and Hagie S (2012). "PACT: Performance Assessment Calculation Tool". John A. Martin \& Associates, INC. Los Angeles, California, US.

14. Haselton CB and Baker JW (2017). "Seismic Performance Prediction Program". Haselton Baker Risk Group, Chico.

15. MacRae G and Clifton GC (2015). "Research on sesimic performance of steel structures". Proceedings of the Steel Innovations 2015, Auckland, New Zealand.

16. Bruneau M and MacRae GA (2017). "Reconstructing Christchurch: a Seismic Shift in Building Structural Systems". The Quake Centre, University of Canterbury, 170 pp.

17. Baird A (2014). "Seismic Performance of Precast Concrete Cladding Systems". PhD Dissertation, University of Canterbury, 544 pp.

18. Porter KA, Kennedy RP and Bachman R (2006). "Creating fragility functions for performance-based earthquake engineering". Earthquake Spectra, 23(2): 471-489.

19. Lilliefors H (1967). "On the Kolmogorov-Smirnov test for normality with mean and variance unknown". Journal of the American Statistical Association, 62: 339-402.

20. Tasligedik AS, Pampanin S and Palermo A (2014). "Low damage non-structural drywalls: Details and their performance". Proceedings of the 2014 NZSEE Conference, Auckland, NZ.

21. Miranda E and Mosqueda G (2011). "Seismic Fragility of Building Interior Cold-formed Steel Framed Gypsum Partition Walls". Background Document FEMA P-58/BD3.9.2, Applied Technology Council, Redwood City, CA, 28 pp.

22. Mosqueda G (2016). "Interior Cold-framed Steel Framed Gypsum Partition Walls". Background Document FEMA P-58/BD-3.9.32, Applied Technology Council, Redwood City, CA, 19 pp.

23. Freeman SA (1976). "Racking tests of high-rise builidng partitions". Journal of the Structural Division, ASCE, 103(8): 1673-1685.
24. Rihal SS (1984). "Behaviour of non-structural building partitions during earthquakes". Proceedings of the Seventh Symposium on Earthquake Engineering, Sarita Prakashan, Meerut, India.

25. Bersofsky AM (2004). "A Seismic Performance Evaluation of Gypsum Wallboard Partitions". Masters Thesis, University of California, San Diego, 302 pp.

26. Lang AF (2007). "Seismic Performance Evaluation of Gypsum Wallboard Partitions". Masters Thesis, University of California, San Diego, 272 pp.

27. Lee TH, Kato T, Matsumiya KS and Nakashima M (2007). "Seismic performance evaluation of non-structural components: drywall partitions". Earthquake Engineering and Structural Dynamics, 36(3): 367-382.

28. Retamales R, Davies R, Mosqueda G and Filiatrault A (2013). "Experimental seismic fragility of cold-formed steel framed gypsum partition walls". Journal of Structural Engineering, 139(8): 1285-1293.

29. Rahmanishamsi E, Soroushian S and Maragakis EM (2014). "System-level experiments on ceiling/piping/partition systems at UNR-NEES site". Proceedings of the Tenth US National Conference on Earthquake Engineering, Alaska, US.

30. Pantoli E, Chen MC, Wang X, Astroza R, Ebrahimian H, Hutchinson TC, Conte JP, Restrepo JI, Marin C, Walsh KD, Bachman RE, Hoehler MS, Englekirk R and Faghihi M (2016). "Full-scale structural and nonstructural building system performance during earthquakes: part II - NCS damage states". Earthquake Spectra, 32(2): 771-794.

31. Petrone C, Magliulo G, Lopez P and Manfredi G (2015). "Seismic fragility of plasterboard partitions via in-plane quasi-static tests". Earthquake Engineering and Structural Dynamics, 44(14): 2589-2606.

32. Dhakal RP, MacRae GA, Pourali A and Paganotti G (2016). "Seismic fragility of suspended ceiling systems used in NZ based on component tests". Bulletin of the New Zealand Society for Earthquake Engineering, 49(1): 45-63.

33. Armstrong (2013). "Ceiling Systems Armstrong Seismic Design Guide - New Zealand Version". AWI Licensing Company, New Zealand.

34. Oosterhoff H and Bain J (2017). "Seismic Design". Trinteriorsystems, New Zealand.

35. Australasia U (2012). "Generic Seismic Design for USG Donn Exposed Grid Suspended Ceilings". USG Interiors Pacific Ltd, Australia.

36. Soroushian S, Rahmanishamsi E, Ryu KP, Maragakis EM and Reinhorn AM (2016). "Experimental fragility analysis of suspension ceiling systems". Earthquake Spectra, 32(2): 881-908.

37. Soroushian S (2016). "Acousitcal Tile of Lay-in Panel Suspended Ceilings". Background Document FEMA P58/BD-3.9.31, Applied Technology Council, Redwood City, CA, 15 pp.

38. Ryu KP, Reinhorn AM and Filiatrault A (2017). "Capacity Evaluation of Suspended Ceiling System". Technical Report MCEER-17-00XX, University at Buffalo, NY, 147 pp.

39. Soroushian S, Ryan KL, Maragakis EM, Sato E, Sasaki T, Okazaki T, Tedesco L, Zaghi AE, Mosqueda G and Alvarez D (2012). "Seismic response of ceiling/sprinkler piping nonstructural systems in NEES TIP/NESS nonstructural/NIED collaborative tests on a full scale 5storey building". Proceedings of the Proceeding of 43rd Structures Congress, Chicago, IL, 29-31 March 2012.

40. Soroushian S, Maragakis EM, Itani M, Pekcan G and Zaghi AE (2011). "Design of a test bed structure for shake table simulation of the seismic performance of nonstructural 
systems". Proceedings of the Proceeding of 42nd Structures Congress, Las Vegas, NV, 14-16 April 2011.

41. Paganotti G, MacRae GA and Dhakal RP (2011). "Development of Typical NZ Ceiling System Seismic Fragilities". Proceedings of the 9th Pacific Conference on Earthquake Engineering, Auckland, New Zealand.

42. Hunt JP and Stojadinovic B (2010). "Seismic Performance Assessment and Probabilistic Repair Cost Analysis of Precast Concrete Cladding Systems for Multistory Buildings". PEER 2010/110, Pacific Earthquake Engineering Research Center, Berkeley, CA, 364 pp.

43. McMullin K, Wong Y, Choi C and Chan K (2004). "Seismic performance states of precast concrete cladding connections". Proceedings of the 13th World Conference on Earthquake Engineering, Vancouver, B.C., Canada.

44. Hyland C, Cowie K and Clifton GC (2007). "Structural Steelwork Connections Guide". Steel Construction New Zealand, Manukau City, NZ.

45. Han SW, Kwon GU and Moon KH (2007). "Cyclic behaviour of post-Northridge WUF-B connections". Journal of Constructional Steel Research, 63(3): 365-374.

46. Lignos DG, Kolios D and Miranda E (2010). "Fragility assessment of reduced beam section moment connections". Journal of Structural Engineering, 136(9): 1140-1150.

47. Roldan R, Della Corte G and Sullivan TJ (2017). "Loss assessment of steel MRF buildings with partial-strength connections". Proceedings of the 16th World Conference on Earthquake Engineering, Santiago, Chile.

48. Della Corte G, Terranciano F, Di Lorenzo G and Landolfo R (2014). "Characterising Bolted End-Plate Beam-Column Joints Using the Component Method". Chapter 5 in Characterising the Seismic Behaviour of Steel BeamColumn Joints for Seismic Design, Ed: Sullivan TJ and O'Reilly GJ, Research report EUCENTRE 2014/01. IUSS Press, Pavia, Italy.
49. Roldan R (2014). "Fragility Functions for End-Plate Bolted Beam-to-Column Joints". Individual Study Report, ROSE School - IUSS Pavia, Italy.

50. Roldan R, Sullivan TJ and Della Corte G (2016). "Displacement-based design of steel moment resisting frames with partially-restrained beam-to-column joints". Bulletin of Earthquake Engineering, 14(4): 1017-1046.

51. EC3 (2010). "Eurocde 3: Design of Steel Structures - Part 1-8: Design of Joints". BSI, United Kingdom, CEN/TC 250.

52. Yeow TZ, Orumiyahei A, Sullivan TJ, MacRae GA, Clifton GC and Elwood KJ (2018). "Seismic performance of steel friction connections considering direct-repair costs". Bulletin of Earthquake Engineering, (Accepted, In Press).

53. Dhakal RP, Pourali A and Saha S (2016). "Simplified seismic loss functions for suspended ceilings and drywall partitions". Bulletin of the New Zealand Society for Earthquake Engineering, 49(1): 64-78.

54. Porter KA, Kennedy RP and Bachman RE (2006). "Developing Fragility Functions for Building Components, Report to ATC-58". Applied Technology Council, Redwood City, CA.

55. Arifin FA, Sullivan TJ, MacRae GA, Mulligan J, Kurata M and Takeda $\mathrm{T}$ (2018). "Evaluating the benefits of retrofitting vulnerable non-structural components: a case study". Proceedings of the 2018 NZSEE conference, Auckland, New Zealand.

56. Rashid M, Dhakal RP and Yeow TZ (2018). "Automatic fire sprinkler systems: an overview of past seismic performance, design standards and scope for future research". Proceedings of the 2018 NZSEE Conference, Auckland, New Zealand. 